\title{
Cloud Computing (SaaS) Adoption as a Strategic Technology: Results of an Empirical Study
}

\author{
Pedro R. Palos-Sanchez, ${ }^{1}$ Francisco J. Arenas-Marquez, ${ }^{2}$ and Mariano Aguayo-Camacho ${ }^{2}$ \\ ${ }^{1}$ Department of Business Management, University of Extremadura, Caceres, Spain \\ ${ }^{2}$ Department of Financial Economy and Operations Management, University of Sevilla, Sevilla, Spain \\ Correspondence should be addressed to Pedro R. Palos-Sanchez; ppalos@unex.es
}

Received 6 February 2017; Accepted 9 May 2017; Published 19 June 2017

Academic Editor: Jose M. Barcelo-Ordinas

Copyright (c) 2017 Pedro R. Palos-Sanchez et al. This is an open access article distributed under the Creative Commons Attribution License, which permits unrestricted use, distribution, and reproduction in any medium, provided the original work is properly cited.

\begin{abstract}
The present study empirically analyzes the factors that determine the adoption of cloud computing (SaaS model) in firms where this strategy is considered strategic for executing their activity. A research model has been developed to evaluate the factors that influence the intention of using cloud computing that combines the variables found in the technology acceptance model (TAM) with other external variables such as top management support, training, communication, organization size, and technological complexity. Data compiled from 150 companies in Andalusia (Spain) are used to test the formulated hypotheses. The results of this study reflect what critical factors should be considered and how they are interrelated. They also show the organizational demands that must be considered by those companies wishing to implement a real management model adopted to the digital economy, especially those related to cloud computing.
\end{abstract}

\section{Introduction}

Cloud computing has attracted a lot of attention in both business and academic spheres in recent times. This is a serviceand applications-related technology run in a distributed network that uses virtual resources and is accessible through networking and Internet standards [1]. Cloud computing has been developed and has evolved out of distributed, grid, and utility computing [2].

There are three main models of cloud service: Infrastructure as a Service (IaaS), based on outsourcing processing and data storage equipment; Platform as a Service (PaaS), which provides developers with a cloud platform to create applications and services; and, lastly, Software as a Service (SaaS), which enables users to access their applications through a browser instead of installing software on their own computers. The last model provides centralized configuration and hosting as well as automatic updates [3], releasing users from installing and maintaining software and simply allowing them access via the Internet $[4,5]$.
The following stand out among the benefits for businesses that are regularly attributed to cloud computing: the reduction in software and hardware resource costs and access to services from anywhere in the world [6,7]; the noncomplex use of cloud-based solutions [8], a scalable [9] marketoriented [10] architecture; the potential to transform business processes [11]; its potential to provide better knowledge management and a tighter link between information systems and management requirements [12] and even its ability to provide competitive advantages, given the reductions in capital outlay and IT-related operating and maintenance costs that enable resources to be redirected toward core business activities [13].

Notwithstanding, the literature also reveals that obstacles and difficulties exist in organizations' adoption of cloud computing, such as reticence regarding information security and protection against nonauthorized access $[14,15]$, the absence of knowledge on the privacy capabilities of service providers [16], a lack of understanding between the organization and the cloud provider as to service scope and 
implementation [17], technical barriers [18], and financing problems that companies in certain sectors might have to address the required investment in technology and qualified IT personnel, especially in the case of small and medium enterprises [11, 19].

Bearing the above in mind, the present paper seeks to find the factors that determine cloud computing adoption by organizations. Numerous studies can be found in the literature that address the use of cloud systems in such companies, ranging from technical issues, such as infrastructure security through proposed new architectures and methods [20-25], efficient data management [26-28], performance and quality of service measurement criteria $[9,29,30]$, and the issues surrounding interoperability standards and difficulties for their integration and customization [31-33]. In other cases, the backbone of research deals with problems more related to business management issues, such as cloud computingassociated opportunities, costs and risks [34-37], and the importance of trust and data privacy [38-44].

Notwithstanding, as will be seen in the following section, research directly related to cloud system adoption and use in companies and organizations is more scarce.

This is the reason why the present study seeks to develop a research model based on the technology acceptance literature that combines several variables proven to be relevant by prior studies. An empirical study has been conducted to test the proposed hypotheses focused on Spanish companies that consider SaaS to be a strategic technology for the execution of their activities.

The remainder of the paper is structured as follows: first, a review is conducted of the prior literature that begins with an analysis of some especially widespread technology acceptance models and then more specifically focuses on papers that are cloud computing-related. Said bibliographical review provides the theoretical foundations for the proposed hypotheses and the eventual proposal for a research model to be formulated. Subsequently, the empirical study methodology used to test the various hypotheses is described and the obtained results are presented. Finally, the results are discussed and the main conclusions are set out along with the study's limitations and future lines of research.

\section{Literature Review}

2.1. Adoption Models. A range of widely used technology acceptance models can be found in the literature that provide useful frameworks for determining the critical factors or variables that influence user ICT adoption and its use and behavior in organizations [56]. Such is the case of Fishbein and Ajzen's [57] Theory of Reasoned Action (TRA). Adopted in many disciplines, this theory explains that the attitudes toward following a given conduct are positively associated with and predict the intention to adhere to said behavior. Also, the attitudes of others toward a particular technology often influence a person's intention to use the same technology.

Ajzen [58] subsequently developed the Theory of Planned Behavior (TPB), adding to the TRA model the beliefs of control and perceived ease of use and behavior control.
This model's key lies in behavior intention and distinguishes between three types of belief: behavioral, normative, and control.

The Davis [59] technology acceptance model (TAM) was subsequently used to find an explanation for the relationship between technology acceptance and adoption and the intention to use it [17]. TAM proposes that perceived usefulness and perceived ease of use are the most critical factors in the technology adoption process and system use [60, 61]. TAM can be considered a special case of TRA in which perceived usefulness and perceived ease of use are considered to be "beliefs and evaluation" that lead to attitude, which in turn leads to intention of use and, finally, to real behavior [62-64].

TAM is a widely accepted model for understanding ICT adoption and usage processes [45] and has been applied in a large amount of research into technology adoption in the organization [65]. TAM consistently explains a large part of variance in the intention of use of a variety of ICT by users in numerous environments and countries [60, 65-68]. Since it first appeared, the TAM model has been widely analyzed and expanded into different variants. Some of the most important evolutions have been the Venkatesh and Davis [46] TAM 2, the Venkatesh et al. [69] Unified Theory of Acceptance and Use of Technology (UTAUT), for example, applied to mobile applications [70], the Wixom and Todd [71] integrated model of technology acceptance and user satisfaction, and the TAM 3 model proposed by Venkatesh and Bala [68] in the field of e-commerce.

Apart from cloud system adoption and use itself, numerous recent studies can be identified within the information systems area that use TAM to explain the adoption of different technologies. Most of these add other external variables to the original TAM model that are considered to be interesting for the research. Thus, it is frequently used in studies on ERP implementation and use in companies [50, 52, 72-82], applications for e-commerce [83], file digitization systems [84], Internet banking [85], mobile social gaming [86], and e-learning platforms [62, 87-90], among many other sectors.

Meanwhile the TOE (Technology-Organization-Environment [91]) framework proposes that technological innovation adoption is influenced by three aspects: organizational context (related to resources and their internal characteristics); environmental context (within which it conducts its business processes); and technological context (formed of organization-related internal and external technologies available in the market used, or not, by the organization) [92]. This is a framework for examining adoption of a range of information systems, products, and ICT services on the organizational (and not the individual) level.

TOE is one of the most widespread theoretical frameworks on ICT adoption [93]. It provides a broad overview of technology adoption and application and predicts the impact on value chain activities and the subsequent diffusion of the factors that influence business decisions [39, 93-95]. However, the weaknesses of the TOE framework may be twofold: TOE's main constructions are not very clear and specific determinants identified within the three contexts vary across different studies [39]. 
Some studies combine aspects of the TAM model and the TOE framework and give, as a result, that the technological and organizational variables influence perceived ease of use and perceived usefulness and that the environmental variables directly influence technology adoption. Apart from being used in studies on cloud systems, as will be seen in the following section, it is possible to identify recent studies in the information systems area that make use of TOE, many of which complement the TAM model. Thus, the literature offers studies in the area of e-commerce [96-101], e-business in developing countries [102], business systems in SMEs [55], websites [103], and Internet use [104, 105], among other things.

Finally, one last widespread theory on technology acceptance in the literature is DOI (Diffusion of Innovations). Published by Rogers in the 1960s, with the latest version dating from 2003, it seeks to explain how, why, and to what degree new ideas and technology are spreading and operating on individual and company levels. This theory states that innovations are communicated via certain channels over time and within the members of a social system [106]. Within companies, innovations are related to independent variables, such as individual characteristics and leadership, the internal characteristics of the organizational structure (centralization, complexity, formalization, size, etc.), and characteristics external to the organization. A number of recent DOI theory-related studies can be found in the area of information systems [30, 102, 107-109].

2.2. Prior Studies on the Adoption of Cloud Computing. Focusing on the specific area of cloud computing, some studies based on theories and models such as a TPB and TAM can be found that analyze adoption and use from the end user perspective. Such is the case of Bhattacherjee and Park [110], who study the motivation of end users to migrate from the client-server model to cloud computing, and Giessmann and Stanoevska [111], who analyze consumer preferences in a PaaS method-based study. Also, based on TAM, Behrend et al. [112] examine student behavior in SaaS method cloud system adoption. Along a similar line, Wu et al. $[47,113]$ propose an acceptance model that combines TAM with other variables and test it in a university institution.

Burda and Teuteberg [48] examine the intention of a sample of university students to use cloud storage. Based on the TAM model, some external variables are added, such as satisfaction, provider's reputation, familiarity, risk, and trust. The study emphasizes the importance of trust to reduce uncertainty and the perception of risk, which are major obstacles for intention of use. Moqbel el al. [114] also use a sample of university students to apply a theoretical framework based, among other things, on the TRA and TAM models. Aspects are included such as compatibility, social influence, and perceived familiarity. Another recent study by Shiau and Chau [2] uses a multiple model comparison approach to examine university student behavioral intention toward cloud computing. These authors test and unify six theories which exhibited adequate explanatory power: service quality, self-efficacy, motivational model, TAM, TRA/TPB, and DOI.
The number of studies directly related to research on cloud computing adoption in companies and organizations is not yet very numerous, although some can be found with different adoption frameworks.

Sharma et al. [115] propose a model by extending TAM with three external constructs (trust, computer self-efficacy, and job opportunity). The proposed factors were found to be important in influencing the cloud computing adoption.

Some other studies propose cloud computing adoption models using TOE, with the variations inherent in this open framework and disparate methodologies, choice of variables, and results. Such is the case of Nkhoma and Dang [116] who use data from a survey to IBM to determine elements that drive or hinder cloud computing adoption. Abdollahzadehgan et al. [19] conduct qualitative research that groups a series of critical success factors for cloud computing for SMEs based on a review of prior studies. Also for SMEs, Alshamaila et al. [117] carry out an exploratory qualitative study of a sample of 15 English companies, identifying some key variables in the adoption process: relative advantage, uncertainty, top management support, geographical restrictions, compatibility, company size, external IT support, and so forth. Finally, also on the basis of the TOE framework, Yang et al. [118] propose a model to analyze the adoption of SaaS based innovations, using a sample of 173 organizations in China. Aspects such as top management support, relative advantage, simplicity, the ability to customize the software, and competitor and partner pressure were significant for adoption.

Another group of studies proposes different cloud system adoption and usage models using elements of DOI Theory [30] and integrating them into the TOE framework [11, 107, 109] in some cases. The Lin and Chen [30] study is based on a semistructured survey of ICT professionals in Taiwan. Their qualitative assessment reveals that companies reject adoption until certain uncertainties related to cloud technology, such as security or standardization, have been reduced. Hsu et al. [107] combine aspects of DOI and TOE to investigate the adoption of cloud computing in Taiwanese companies. A sample of 200 companies is used to empirically test a basic model that, apart from including the intention of adoption and use, also takes into consideration price mechanisms and implementation models. These authors conclude that the expected benefits, the perceived risks and issues, ICT resources, and personnel are factors that determine adoption. Meanwhile, Low et al. [109] investigate the factors that affect cloud computing adoption in the high-tech industry in Taiwan. They collect data from 111 firms and find that trading partner pressure, competitive pressure, relative advantage, firm size, and top management support have a significant effect on the adoption. Along the same line, Oliveira et al. [11] propose a model that also combines elements of DOI Theory and the TOE framework. These authors distinguish three types of adoption factors: individual factors, internal organizational structure, and the organization's external characteristics. Results from data mined from a sample of 369 companies in Portugal indicate that aspects such as relative advantage, 
complexity, technological readiness, top management support, and firm size have a direct effect on cloud systems being adopted in a company.

Finally, the recent study by Gangwar et al. [45] develops an integrated TAM-TOE model that includes a range of exploratory features and is tested using a sample of $280 \mathrm{com}-$ panies in various sectors in India. The authors suggest that the variables in technological and organizational contexts have a direct effect on the TAM model and, consequently, an indirect effect on adoption. The combined model proposes an indirect impact on adoption of the environmental variables. The conclusions of the study show that all the variables of the three contexts are major determinants of the adoption of cloud computing, whether directly or indirectly.

\section{Research Model and Hypotheses}

After analyzing a number of frameworks and theories used in the various studies on technology acceptance, it was decided to use TAM in the present research with the addition to the original model of other external variables considered to be especially interesting for the present research. The choice of TAM is justified by its robustness and its widespread acceptance for understanding the ICT adoption and usage processes in a great deal of prior research. This enables authors to apply scales that have already been developed and empirically validated on many occasions. As such, the main constructs that explain the attitudes toward the use of technology in the TAM model have been tested on many occasions and their use in the cloud computing context can be considered to be both a valid and a well-supported choice.

In other respects, the TAM model has frequently been expanded in many studies through the addition of other variables considered to be interesting or that have been significant in prior research. According to the original model proposed by Davis [119], the expectation is that the other factors not implicitly included in TAM influence attitude toward using (ATU) and behavioral intention to use (BIU) via perceived usefulness (PU) and perceived ease of use (PEOU).

The review of studies that significantly integrate TAM with other external variables and acceptance theories has therefore helped in the selection of some of the constructs incorporated in the present research's structural model and also in the formulation of the associated hypotheses. It must be borne in mind that there is no generalizable common body of variables outside TAM to explain technology adoption that is applicable to any context [120]. Therefore, selecting some external variables to complement the original TAM model, with literature support and the adaptation of characteristics to fit this study, has been a major task in the present research.

An explanation will be given in the following of all the variables included in the model and the relationships between them that have led to the formulation of the different research hypotheses. We therefore begin with those of the TAM model.

3.1. Technology Acceptance Model (TAM) Variables. The TAM model establishes causal relationships among perceived usefulness (PU), perceived ease of use (PEOU), attitude toward using (ATU), and behavioral intention to use (BIU).
ATU reflects favorable or unfavorable feelings toward the use of any given technology, while BIU is the degree of prior behavior possessed when using said technology [121]. The ATU construct therefore represents the adoption of a positive or negative conduct toward an innovation and directly influences BIU. The introduction of BIU as a mediating variable is important, as it is thought that an intention always precedes a behavior and this thus increases the model's predictive value [57].

$\mathrm{PU}$ is defined as the degree to which individuals believe that using a particular system would improve their performance. It would be a reflection of the subjective likelihood that when potential users use the technology, this increases their work performance within the context of an organization. PEOU, meanwhile, refers to the degree that an individual believes that the use of a particular system would be effort-free [59].

The TAM model proposes that PU and PEOU contribute to generating a positive attitude toward technology use and, therefore, have a significant influence on ATU. This last variable in turn directly influences BIU. In other respects, the model proposes that $\mathrm{PU}$ is also a direct determinant of BIU. According to Davis [59], attitudes are made up in part by affectivity (represented by ATU), but the direct PUBIU relationship is based on cognitive decision-making rules aimed at improving work performance and has no reason to activate said affectivity. In other words, users might not like a system and might have a negative attitude toward it but will nonetheless use it, as it is perceived as advantageous for their work performance. Finally, the model also proposes that PEOU significantly influences PU. Apart from in studies by Davis himself, relationships between TAM variables have been significant in numerous prior studies on technology acceptance. On the basis of the above, the hypotheses that come from the application of the TAM model are as follows:

$\mathrm{H}_{1}$. PEOU has a positive effect on $\mathrm{PU}$ of cloud computing.

$\mathrm{H}_{2}$. PEOU has a positive effect on attitudes to cloud computing (ATU).

$\mathrm{H}_{3}$. PU has a positive effect on attitudes to cloud computing (ATU).

$\mathrm{H}_{4}$. PU has a positive effect on the intention to use cloud computing (BIU).

$\mathrm{H}_{5}$. ATU has a positive effect on the intention to use cloud computing (BIU).

\subsection{External Variables}

3.2.1. Top Management Support (TMS). Top management support is broadly considered to be a key success factor in technological projects [122]. There are numerous recent studies that, with methodological differences and making use of different adoption frameworks, include top management support (TMS) among the variables that might significantly affect technology acceptance in a company $[50,55,96,104$, $123,124]$, and some of these focus specifically on the sphere of cloud computing [11, 19, 45, 109, 118]. 
The involvement of top management during ICT implementation is justified, first, because their broader organizational vision enables them to identify business opportunities afforded by the exploitation of said technologies [125]. In addition, as Low et al. [109] state, top management plays a major role as the implementation of cloud computing entails the integration of resources and process reengineering. Therefore, the investment that this technology involves for organizations can have major implications for organizations, which ratifies that top management must remain active during its implementation [64] and significantly influence its performance [126].

For Yang et al. [118], TMS is especially important for adopting a technology in SMEs, where CEO or equivalent usually has the final vision of the organization's ICT strategy and the investments that derive from it [127]. For the majority of companies of this type, the transition from the traditional way of working with ICT to the changes involved in cloud computing is a strategic decision, and a positive attitude of company executives toward innovation will most likely favor its adoption.

TMS can translate into tasks being appropriately undertaken, including system selection, process planning, policy formulation, design of a team of experts, coordination of implementation in the organization's different centers, resource allocation and architecture definition, support for process reengineering, performance assessment, and management of the generated expectations and of organizational, cultural, and structural changes $[45,50,128]$. Some authors also insist on the need to influence the generation of positive attitudes toward technology use [129-131].

Therefore, TMS can be considered to be one of the best predictors of organizations' adoption of innovations in information systems [132]. Top management can provide a stimulus to change, basically in communication and in reinforcing the values of innovation, as top managers have an articulated vision of the organization [133]. Along the same line, Gangwar et al. [45] conclude that top management plays an effective role in motivating employees' work behavior and in convincing them of the importance of using cloud computing. For Bueno and Salmerón [50] TMS is defined as the active involvement of head managers in issues linked with the success of technology implementation. This active involvement is primarily brought to bear through leadership and ongoing contact with those who are directly linked with the ICT planning processes $[64,134]$. Users tend to assimilate the management's expectations through these measures and also perceive that an organization's heads support its implementation [135]. This drives up employees' favorable attitudes toward ICT [136]. In contrast, the lack of free and flowing communication between the management and the rest of the personnel could be a major problem in an information systems renovation project [137].

Taking all the foregoing into account, it seems evident that TMS demands appropriate communication about cloud systems to be led, reporting their advantages and difficulties and managing specific meetings and gatherings. As such, a direct influence of TMS on communication can be presupposed. TMS is also expected to have a positive influence on users' perceptions of the degree to which the new system will improve their performance (PU) and of the efforts that its implementation and use will require (PEOU). The direct TMS-PU/PEOU relationship is included in different prior studies on technology adoption $[45,64,77,136]$. We therefore formulate the following hypotheses:

$\mathrm{H}_{6}$. TMS has a positive effect on communication (C) about cloud computing.

$\mathrm{H}_{7}$. TMS has a positive effect on PEOU of cloud computing.

$\mathrm{H}_{8}$. TMS has a positive effect on PU of cloud computing.

3.2.2. Training (T). Training is described as the degree to which a firm instructs its employees in the use of a tool in terms of quality and quantity [138]. Although continuous training during the entire useful life of an information system is always recommendable, the main training efforts are usually carried out during the first stages of its implementation [139]. Deficient end user training can be a decisive factor in a technology's end use intention [123]. In a theoretical extension of the TAM model, Venkatesh and Davis [46] demonstrate that the training techniques and methodologies designed to improve users' self-efficacy at the computer are essential for improving acceptance of the technology. Along a similar line, Amoako-Gyampah and Salam [49] state that perceptions of ease of use are affected by training during the first stages of learning.

An organization needs to train its employees and develop knowledge for the efficient future use of a complex information system such as cloud computing. This reduces the possibility of stress and provides greater motivation and a better understanding of the benefits of the cloud system for the tasks that personnel execute [45]. In short, training can have a positive effect on both PEOU and PU. Training's influence on PEOU and PU has been clearly demonstrated in a range of prior studies of information systems, such as [49$52,64,140]$. As far as specific studies of cloud computing are concerned, the study by [45] addresses the direct relationship between training and both PU and PEOU.

In addition, cloud technologies can be difficult to learn in a professional environment as they cover a broad gamut of techniques and parameters that have to be taken into account [30]. In these cases, training enables users to share the common problems that emerge when working with the system, and this can have the effect of improving the communication linked to same [50]. Therefore, cloud system training programs set up by the company are to be expected to improve fluidity of communication about the systems and deal with different aspects of their use.

The above analyzed aspects reveal several relationships which lead us to formulate the following hypotheses:

$\mathrm{H}_{9}$. Training (T) has a positive effect on PEOU of cloud computing.

$\mathrm{H}_{10}$. Training (T) has a positive effect on communication (C) about cloud computing. 
$\mathrm{H}_{11}$. Training (T) has a positive effect on PU of cloud computing.

3.2.3. Communication (C). Communication can be defined as the information transfer process among team or organization members [141]. When a new information system is introduced, employees should be informed in advance of the scope, objectives, tasks, and updates that the implementation of the system will entail to enable them to accept the changes that will occur $[142,143]$. Communication is realized through the existence of periodic meetings to discuss the new system to be adopted and through the existence of information regarding its advantages and limitations [119].

Quality communication is produced when members use a certain amount of time to formally or informally exchange information and opinions [141]. This type of communication helps distribute ideas more widely and improves knowledge transfer, especially when the information being transmitted is credible and comes from reliable sources [144].

Therefore, effective communication is needed to reduce uncertainty and the risk of confusion [141], and also the effort required to use a system [52], and helps develop the confidence and information sharing required to address changes and, in the final instance, accept the technology [49].

To the contrary, a lack of communication is directly related to the failure of many information system implementation projects [49]. For Trube and Collins [145], when communication is lacking, disputes and conflicts arise that negatively impact work performance. For their part, Lin and Chen [30] demonstrate that, from a more professional point of view, a lack of communication in the sphere of cloud computing can complicate the existent dynamic between different developers and, as a consequence, the product's perceived end utility.

Taking the above into account, and as communication is what facilitates access to information about the system's benefits and its dissemination among all an organization's members, it is to be expected that frequency and quality of communication improve the technology's perceived ease of use and perceived usefulness $[49,140]$. The influence of communication on PEOU and PU has been demonstrated in several prior studies $[49,52,140,146]$. This leads us to propose the following hypotheses:

$\mathrm{H}_{12}$. Communication (C) has a positive effect on PEOU of cloud computing.

$\mathrm{H}_{13}$. Communication (C) has a positive effect on PU of cloud computing.

3.2.4. Technological Complexity (TC). Technological complexity is understood as the degree to which an innovation is perceived as relatively difficult to understand and use [147, 148]. Some aspects usually associated with complexity are the degree of difficulty of the skills that employees are required to have to use technologies or the difficulty of integrating these technologies into work [149]. In the specific case of cloud computing, other aspects could be the time required to execute tasks, the integration of the applications into the cloud infrastructure, the design of interfaces, or the efficiency of data transfer [45]. In short, technological complexity can influence the adoption of a cloud solution [150].

As complexity can have a knock on effect, on a technology's perceived degree of difficulty of use, it can be supposed that it will significantly influence PEOU [151]. Several studies exist in different areas that demonstrate that complexity has an inverse relationship with perceived ease of use. This is the case of Bueno and Salmerón [50], Son et al. [64], and, more specifically, the study by Gangwar et al. [45] on acceptance of cloud computing. This last study also provides evidence of a significant inverse relationship between complexity and PU.

In addition, other authors concur on the negative influence that technological complexity might have on BIU, based on aspects unrelated to attitudes to the system generated by PU and PEOU. The cloud environment offers the ability to share resources instantaneously to adjust workload. Nevertheless, even though a company wishes to adopt a solution of this type, it must address challenges that derive from any limitations it might have due to a lack of experience or through not having the necessary ICT specialists for its implementation [11]. Furthermore, cloud systems are also a challenge to ensuring business processes and data privacy in a shared environment [152]. In other words, a company might perceive that cloud systems are useful and easy to use for employees, but their implementation entails a series of complex technological challenges that it cannot address. A number of empirical studies have proven this inverse relationship between technological complexity and behavioral intention to use $[11,124]$. Taking the above into account, we formulate the following hypotheses:

$\mathrm{H}_{14}$. Technological complexity (TC) has a negative effect on PU of cloud computing.

$\mathrm{H}_{15}$. Technological complexity (TC) has a negative effect on PEOU of cloud computing.

$\mathrm{H}_{16}$. Technological complexity (TC) has a negative effect on the behavioral intention to use (BIU) cloud computing.

3.2.5. Organization Size (OS). There are numerous prior research studies that show that organization size is one of the most important determinants of technological innovations [109]. In technology adoption studies, organization size is usually measured on the basis of aspects such as the company's volume of business or mean number of employees. These indicators have also been used in the present research.

The literature shows that small firms do not usually adopt the newest technologies $[11,153]$ despite being able to be more flexible and versatile when coordinating the required changes [19] and that it is the largest companies that are more active as far as innovation is concerned [54]. In fact, within the sphere of information systems, most empirical studies have consistently found that organization size is positively related to innovation use $[39,154,155]$. The main explanation for this lies in the fact that large companies possess greater resources that enable them to assume the risks associated with the technological innovation adoption process [102, 155-157]. These companies' financial resources enable them to bear 


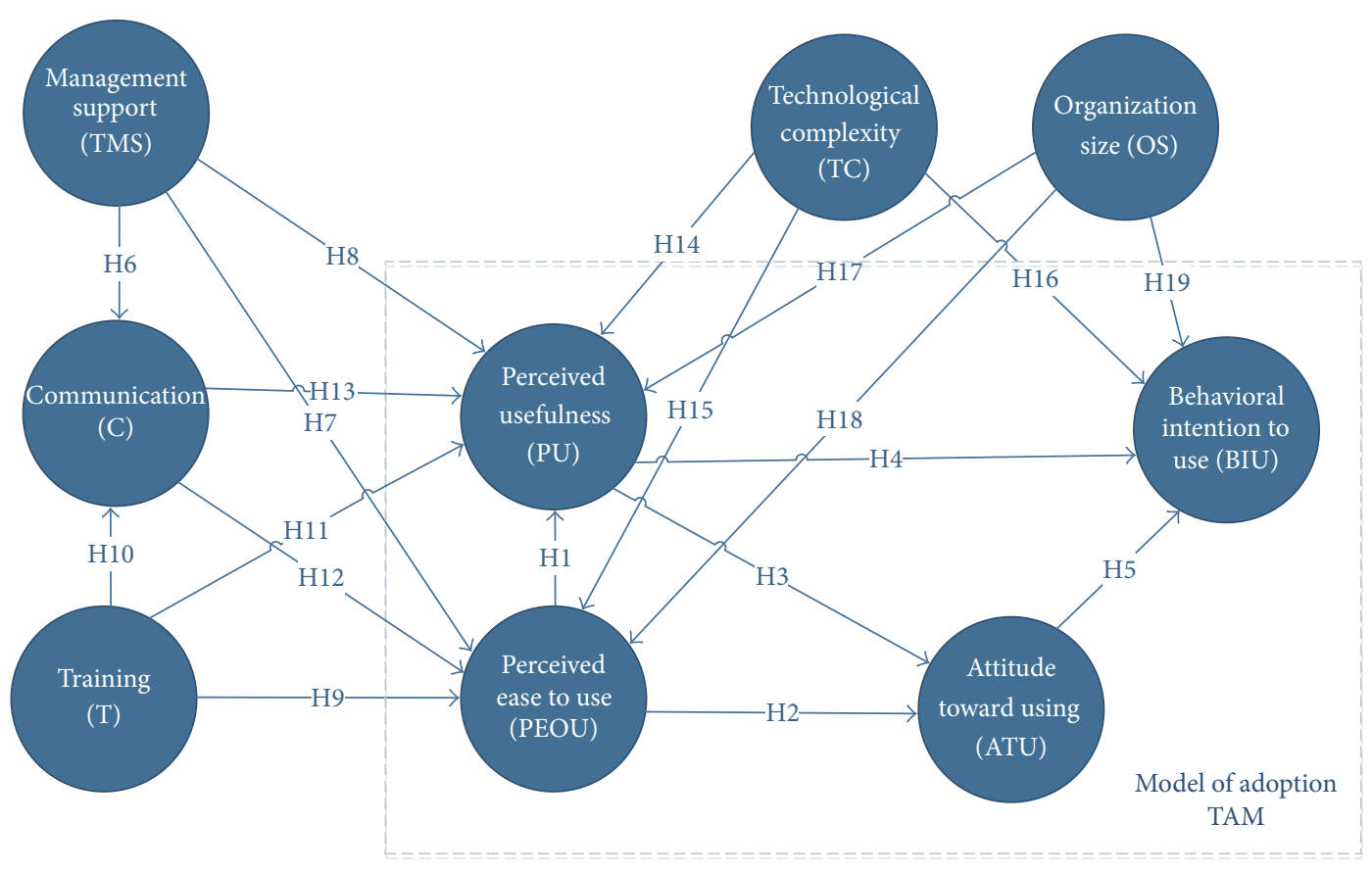

FIGURE 1: Research model.

the costs associated with installation, integration, personnel training, and maintenance, among other things [107].

Organization size is, therefore, another organizational factor that can influence the adoption of cloud computing, apart from company attitudes. Its direct relationship with BIU has been demonstrated in a number of recent studies in the field $[11,109]$.

In other regards, the influence of organization size on perceived usefulness and perceived ease of use has been examined to a more limited extent. However, according to the original TAM model proposed by Davis [59], external variables can be expected to indirectly influence ATU and BIU via PEOU and PU. Taking the above into account, we propose the following hypotheses:

$\mathrm{H}_{17}$. Organization size (OS) significantly influences PU of cloud computing.

$\mathrm{H}_{18}$. Organization size (OS) significantly influences PEOU of cloud computing.

$\mathrm{H}_{19}$. Organization size (OS) has a positive effect on the behavioral intention to use (BIU) cloud computing. On the basis of all the above, the research model proposed in the present research is shown in Figure 1.

\section{Research Methodology}

4.1. Measurement. A questionnaire was prepared to assess the proposed model aimed at firms in a variety of economic sectors located in the Andalusian Autonomous Community (Spain). All these firms are characterized by using cloud computing (SaaS model) as a strategic tool in their activities. The questionnaire was developed by the researchers in collaboration with and monitored by information systems experts at the same university. The items in the questionnaire were based on a review of previous studies on technology adoption. Table 1 gives all the items used to measure each of the variables in the model together with the main prior research studies used as sources.

All constructs were measured using a 5-point Likert scale from 1 ("strongly disagree") to 5 ("strongly agree"). The only exception was the construct relating to organization size, for which two indicators commonly used for its measurement were used: number of employees and annual business volume $[39,154,155]$.

The questionnaire was piloted in 22 organizations not included in the subsequent sample. The respondents filled out the questionnaire and gave feedback on the difficulty and clarity of the proposed questions. This preliminary test confirmed the validity and reliability of the scales used in the final questionnaire.

4.2. Data Collection. After contacting business organizations in the IT sector in Andalusia, a number of Chambers of Commerce in the region, and public initiatives designed to foment migration to and use of business cloud computing solutions, we obtained a census of 615 Andalusian companies in different economic sectors that regularly use SaaS and for which the technology is a strategic tool in the execution of their activities. All these firms were contacted and sent the questionnaire online backed up with telephone supervision. A final number of 161 questionnaires were obtained of which 150 were considered valid and suitable for testing the proposed technological model.

The questionnaire was answered by the people with the greatest knowledge of the cloud computing adoption process in the organizations, irrespective of their positions in the 
TABLE 1: Operationalization of constructs.

\begin{tabular}{|c|c|c|}
\hline Construct & Items & Adapted \\
\hline Perceived usefulness & $\begin{array}{l}\text { (PU1) Using cloud computing enables tasks to be completed more quickly. } \\
\text { (PU2) Using cloud computing improves work performance. } \\
\text { (PU3) Using cloud computing increases work productivity. } \\
\text { (PU4) Using cloud computing boosts work effectiveness. }\end{array}$ & [45-47] \\
\hline Perceived ease of use & $\begin{array}{l}\text { (PEU1) Interaction with cloud computing services is clear and easily understood. } \\
\text { (PEU2) Working with cloud computing does not require much mental effort. } \\
\text { (PEU3) Cloud computing services are easy to use. } \\
\text { (PEU4) What you want to do can be easily found in cloud computing services. }\end{array}$ & {$[45,46,48]$} \\
\hline Attitude toward using & $\begin{array}{l}\text { (ATU1) Cloud computing provides access to most data. } \\
\text { (ATU2) Cloud computing is better than the previous information system in the company. } \\
\text { (ATU3) Cloud computing provides accurate information. } \\
\text { (ATU4) Cloud computing provides integrated, timely, and reliable information. }\end{array}$ & {$[49,50]$} \\
\hline Behavioral intention to use & $\begin{array}{l}\text { (BIU1) The company expects the cloud computing services to be used. } \\
\text { (BIU2) The company expects the information provided by the new cloud computing-based } \\
\text { system to be useful. }\end{array}$ & {$[47,50]$} \\
\hline Top management support & $\begin{array}{l}\text { (TMS1) Top management is interested in cloud computing. } \\
\text { (TMS2) Top management understands the importance of cloud computing. } \\
\text { (TMS3) Top management supports the implementation of cloud computing. } \\
\text { (TMS4) Top management understands the opportunities provided by cloud computing. }\end{array}$ & {$[11,45,50]$} \\
\hline Training & $\begin{array}{l}\text { (T1) Full training was received on cloud computing services. } \\
\text { (PT2) Received training gives confidence in the cloud computing system. } \\
\text { (PT3) Training on cloud computing was sufficiently broad and detailed. } \\
\text { (PT4) The trainers were knowledgeable of cloud computing services and passed their } \\
\text { knowledge on to employees. }\end{array}$ & {$[45,49,51,52]$} \\
\hline Communication & $\begin{array}{l}\text { (C1) There is fluid communication regarding cloud computing services. } \\
\text { (C2) There are no obstacles to addressing the topic of cloud computing. } \\
\text { (C3) Honest information was received about cloud computing services. }\end{array}$ & {$[49,50,52]$} \\
\hline Technological complexity & $\begin{array}{l}\text { (TC1) It is hard to understand what cloud computing services do. } \\
\text { (TC2) Using cloud computing services takes up too much time. } \\
\text { (TC3) A lot of effort is required to learn how to use cloud computing services. } \\
\text { (CT4) In general, cloud computing is very complex to use. }\end{array}$ & {$[11,53]$} \\
\hline Organization size & $\begin{array}{l}\text { (OS1) Please indicate the annual business volume in the organization. } \\
\text { (OS2) Please indicate the number of employees in the organization. }\end{array}$ & {$[11,54,55]$} \\
\hline
\end{tabular}

companies (directors, chief information officers, IT managers, etc.). Thus a "key informants" methodology for data collection was used. This is a common focus in information systems-related empirical analyses $[9,11]$.

A series of recommendations were followed during the design of the study questionnaire to avoid the common method bias associated with the responses given to a range of different questionnaire questions [158, 159]. First, clear, concise questions were asked using very familiar terms for respondents. Second, confidentiality of responses was guaranteed so that respondents could answer honestly. Lastly, random changes were made to the order in which some of the questions were asked. After data collection, the Harman single factor test was used as a common method bias after control measure [160-162]. The test detected no single factor that could explain most of the total variance, which suggests that a bias is very unlikely.

4.3. Data Analysis Method. With respect to testing the conceptual model's hypotheses, the Partial Least Squares (PLS) technique was applied to estimate variance-based structural equations models (SEM). SmartPLS 3 software [163] was chosen to assess reliability and validity of the measurement model and to test the structural model, both for its graphic resolution capacity and for the set of applied statistical methods. SEM are a good choice when seeking to find the simultaneous behavior of dependence relationships and enable us to go further than other multivariate techniques, such as multiple regression and factor analysis [164]. 
TABLE 2: Cronbach's alpha and composite reliability.

\begin{tabular}{lcc}
\hline Constructs & Cronbach's alpha & $\begin{array}{c}\text { Composite } \\
\text { reliability (CR) }\end{array}$ \\
\hline Attitude toward using & 0.871 & 0.912 \\
Top management support & 0.930 & 0.951 \\
Technological complexity & 0.899 & 0.930 \\
Communication & 0.795 & 0.878 \\
Training & 0.966 & 0.975 \\
Behavioral intention to use & 0.800 & 0.908 \\
Perceived ease of use & 0.884 & 0.920 \\
Perceived usefulness & 0.934 & 0.953 \\
Organization size & 0.832 & 0.919 \\
\hline
\end{tabular}

TABLE 3: Average Variance Extracted (AVE) of each construct.

\begin{tabular}{lc}
\hline Constructs & AVE \\
\hline Attitude toward using & 0.722 \\
Top management support & 0.828 \\
Technological complexity & 0.769 \\
Communication & 0.706 \\
Training & 0.908 \\
Behavioral intention to use & 0.832 \\
Perceived ease of use & 0.742 \\
Perceived usefulness & 0.836 \\
Organization size & 0.849 \\
\hline
\end{tabular}

PLS was chosen for several reasons: first, PLS does not impose normality requisites on the data and is a technique that is indicated for predicting dependent variables in small samples, given a certain degree of quality in the measurement model $[165,166]$. Thus, it adapts well to our final 150organization sample. In addition, PLS is more appropriate when the objective is to predict and investigate relatively new phenomena [167], as is the case of cloud computing. Finally, PLS is a widely used SEM assessment method in business management research on information systems [168-170] and on cloud computing $[11,54,118]$.

\section{Results}

5.1. Measurement Model. Cronbach's Alpha and Composite Reliability (CR) were used to measure construct reliability.

These enable construct reliability consistency to be measured on the basis of its indicators [171], that is, the rigor with which these items are measuring the same latent variable. Values nearer to 1 indicate greater reliability.

Table 2 gives the calculations of the two coefficients for all the model constructs. As can be observed, all the alpha coefficients present values much greater than 0.7 , which is the bottom threshold that is usually set for accepting construct reliability [172]. CR coefficients confirm that all the constructs have great internal consistency as they present values between 0.878 and 0.975 , which are well above the minimum required level of $0.7[173,174]$.

Average Variance Extracted (AVE) was used to assess convergent validity (see Table 3 ). This provides information about the amount of variance a construct manages to obtain from its indicators compared to the amount of variance due to measurement error [175].

Discriminant validity indicates the degree to which a given construct is different from other constructs. To determine discriminant validity, first the analysis shown in Table 4 was performed.

This consisted of testing that each construct's AVE square root (in the diagonal in the table) is greater than the correlation between the construct in question and the remaining constructs in the model [175]. As can be observed, this requisite is complied with in all cases.

The second analysis for discriminant validity consists of validating the cross-loadings matrix of all the indicators with their respective constructs. Loads $(\lambda)$ indicate correlations between the scores of a construct and its indicators. Crossloadings reflect the correlations between a construct's scores and the scores of other constructs' indicators [176].

If a measure loads more strongly on other constructs than its own, its inclusion has to be reconsidered, as it is not clear which construct it is reflecting.

Each item set should be expected to load more on it respective constructs than on the indicators of other constructs. As Table 5 shows, all items achieve a higher value with their own construct than the other latent variables.

From this point of view, discriminant validity would also be achieved in all cases.

The second analysis for discriminant validity consists of validating the cross-loadings matrix of all the indicators with their respective constructs. Loads $(\lambda)$ indicate correlations between the scores of a construct and its indicators. Crossloadings reflect the correlations between a construct's scores and the scores of other constructs' indicators [176]. If a measure loads more strongly on other constructs than its own, its inclusion has to be reconsidered, as it is not clear which construct it is reflecting. Each item set should be expected to load more on its respective constructs than on the indicators of other constructs. As Table 5 shows, all items achieve a higher value with their own construct than the other latent variables. From this point of view, discriminant validity would also be achieved in all cases.

Finally, with respect to the individual reliability of each construct's reflective indicators, as can be seen in Table 5 , all the items have high loads $(\lambda)$ and do not need to be filtered. A manifest variable's communality $\left(\lambda^{2}\right)$ is the part of its variance that is explained by a factor or construct [177]. A value of $\lambda>=0.707$ indicates that each measure represents at least $50 \%(0.7072=0.5)$ of underlying construction variance [176], whereby it is common to set this value as a minimum level for its acceptance as part of the construct [178]. All the loadings of all the items included in the research model are observed to be above this threshold and can therefore be considered reliable.

5.2. Structural Model. With the measurement model shown to have adequate reliability and validity levels, the structural model is analyzed. During this stage, the hypotheses are tested to find whether they obey the established relationships between the various constructs of the proposed research model [176, 179-181]. 
TABle 4: Correlations and AVEs.

\begin{tabular}{lcccccccc}
\hline & ATU & TMS & TC & C & T & BIU & PEOU & PU \\
\hline ATU & $\mathbf{0 . 8 5}$ & & & & & & & \\
TMS & 0.537 & $\mathbf{0 . 9 1}$ & & & & & \\
TC & -0.302 & -0.226 & $\mathbf{0 . 8 7 7}$ & & & & \\
C & 0.631 & 0.608 & -0.300 & $\mathbf{0 . 8 4 1}$ & & & \\
T & 0.484 & 0.443 & -0.153 & 0.546 & $\mathbf{0 . 9 5 3}$ & & \\
BIU & 0.639 & 0.443 & -0.335 & 0.541 & 0.466 & $\mathbf{0 . 9 1 2}$ & & \\
PEOU & 0.763 & 0.540 & -0.434 & 0.665 & 0.417 & 0.571 & $\mathbf{0 . 8 6 2}$ & \\
PU & 0.724 & 0.498 & -0.225 & 0.512 & 0.458 & 0.664 & 0.658 & $\mathbf{0 . 9 1 4}$ \\
OS & -0.346 & -0.241 & 0.155 & -0.364 & -0.182 & -0.110 & -0.457 & -0.367 \\
\hline
\end{tabular}

TABLE 5: PLS loadings and cross-loadings.

\begin{tabular}{|c|c|c|c|c|c|c|c|c|c|}
\hline Item & ATU & TMS & TC & $\mathrm{C}$ & $\mathrm{T}$ & BIU & PEOU & $\mathrm{PU}$ & OS \\
\hline TMS1 & 0.854 & 0.376 & 0.486 & -0.129 & 0.348 & 0.337 & 0.359 & 0.369 & -0.179 \\
\hline TMS2 & 0.946 & 0.526 & 0.599 & -0.219 & 0.409 & 0.437 & 0.511 & 0.488 & -0.264 \\
\hline TMS3 & 0.953 & 0.501 & 0.547 & -0.223 & 0.391 & 0.391 & 0.523 & 0.441 & -0.228 \\
\hline TMS4 & 0.883 & 0.53 & 0.567 & -0.236 & 0.456 & 0.432 & 0.547 & 0.496 & -0.199 \\
\hline ATU1 & 0.365 & 0.814 & 0.49 & -0.196 & 0.372 & 0.513 & 0.642 & 0.608 & -0.263 \\
\hline ATU2 & 0.464 & 0.812 & 0.563 & -0.252 & 0.419 & 0.586 & 0.607 & 0.615 & -0.288 \\
\hline ATU3 & 0.507 & 0.901 & 0.572 & -0.254 & 0.483 & 0.586 & 0.635 & 0.657 & -0.307 \\
\hline ATU4 & 0.484 & 0.868 & 0.516 & -0.325 & 0.366 & 0.481 & 0.711 & 0.576 & -0.319 \\
\hline $\mathrm{C} 1$ & 0.502 & 0.553 & 0.867 & -0.214 & 0.428 & 0.409 & 0.551 & 0.416 & -0.347 \\
\hline $\mathrm{C} 2$ & 0.374 & 0.484 & 0.787 & -0.237 & 0.333 & 0.42 & 0.454 & 0.358 & -0.169 \\
\hline C3 & 0.615 & 0.55 & 0.865 & -0.296 & 0.575 & 0.521 & 0.643 & 0.497 & -0.367 \\
\hline TC1 & -0.168 & -0.165 & -0.141 & 0.724 & -0.019 & -0.034 & -0.353 & -0.079 & 0.264 \\
\hline TC2 & -0.168 & -0.267 & -0.263 & 0.932 & -0.08 & -0.366 & -0.383 & -0.25 & 0.08 \\
\hline TC3 & -0.221 & -0.304 & -0.264 & 0.922 & -0.193 & -0.312 & -0.402 & -0.198 & 0.178 \\
\hline TC4 & -0.234 & -0.297 & -0.343 & 0.914 & -0.203 & -0.359 & -0.396 & -0.217 & 0.09 \\
\hline $\mathrm{T} 1$ & 0.471 & 0.473 & 0.559 & -0.194 & 0.936 & 0.472 & 0.442 & 0.454 & -0.187 \\
\hline $\mathrm{T} 2$ & 0.407 & 0.439 & 0.475 & -0.117 & 0.949 & 0.427 & 0.35 & 0.417 & -0.179 \\
\hline T3 & 0.4 & 0.484 & 0.547 & -0.135 & 0.974 & 0.44 & 0.422 & 0.443 & -0.173 \\
\hline $\mathrm{T} 4$ & 0.407 & 0.446 & 0.493 & -0.132 & 0.953 & 0.435 & 0.367 & 0.43 & -0.154 \\
\hline BIU1 & 0.363 & 0.491 & 0.454 & -0.344 & 0.389 & 0.893 & 0.462 & 0.525 & -0.072 \\
\hline BIU2 & 0.438 & 0.659 & 0.527 & -0.275 & 0.456 & 0.93 & 0.57 & 0.673 & -0.124 \\
\hline PEOU1 & 0.496 & 0.704 & 0.663 & -0.349 & 0.399 & 0.481 & 0.903 & 0.631 & -0.495 \\
\hline PEOU2 & 0.388 & 0.533 & 0.472 & -0.278 & 0.3 & 0.412 & 0.802 & 0.37 & -0.363 \\
\hline PEOU3 & 0.436 & 0.688 & 0.57 & -0.491 & 0.336 & 0.619 & 0.887 & 0.597 & -0.299 \\
\hline PEOU4 & 0.526 & 0.681 & 0.565 & -0.364 & 0.389 & 0.444 & 0.851 & 0.623 & -0.41 \\
\hline PU1 & 0.487 & 0.638 & 0.468 & -0.162 & 0.446 & 0.541 & 0.583 & 0.89 & -0.355 \\
\hline PU2 & 0.468 & 0.669 & 0.436 & -0.193 & 0.427 & 0.616 & 0.576 & 0.942 & -0.284 \\
\hline PU3 & 0.448 & 0.678 & 0.427 & -0.229 & 0.415 & 0.62 & 0.595 & 0.916 & -0.347 \\
\hline PU4 & 0.419 & 0.66 & 0.54 & -0.234 & 0.389 & 0.647 & 0.649 & 0.908 & -0.357 \\
\hline OS1 & -0.285 & -0.398 & -0.392 & 0.205 & -0.183 & -0.125 & -0.505 & -0.387 & 0.957 \\
\hline OS2 & -0.127 & -0.199 & -0.252 & 0.046 & -0.147 & -0.066 & -0.296 & -0.269 & 0.885 \\
\hline
\end{tabular}

The basic measure to determine predictability of endogenous variables is $R^{2}$. This can be defined as the amount of construct variance explained by the model. According to Chin [179], benchmark $R^{2}$ values of $0.67,0.33$, and 0.19 can be considered to be strong, moderate, and weak, respectively. Falk and Miller [182] indicate that when $R^{2}$ values are under 0.1 the relationships formulated as hypotheses have a very low predictive level despite being statistically significant. The model's latent variables that are not endogenous have no $R^{2}$ value. This is the case of the independent variables: TMS, TC, $\mathrm{OS}$, and $\mathrm{T}$.

Table 6 gives all the endogenous variables' $R^{2}$ values. All the values can be observed to amply exceed the minimum 0.1 threshold set by Falk and Miller [182]. Meanwhile, following Chin [179], the $R^{2}$ value for ATU demonstrates the existence of a strong predictive power, while BIU (0.548), PU (0.497), 
TABLE 6: $R^{2}$ and $Q^{2}$.

\begin{tabular}{lcc}
\hline Constructs & $R^{2}$ & $Q^{2}$ \\
\hline Attitude toward using (ATU) & 0.669 & 0.479 \\
Communication (C) & 0.465 & 0.302 \\
Behavioral intention to use (BIU) & 0.548 & 0.415 \\
Perceived ease of use (PEOU) & 0.576 & 0.412 \\
Perceived usefulness (PU) & 0.497 & 0.395 \\
\hline
\end{tabular}

PEOU (0.576), and C (0.465) values are moderate to strong. In short, even though additional factors can evidently exist, the model can be stated to be highly predictive and a large part of the variables' variances are explained by the same.

Table 6 also includes the Stone-Geisser test $\left(Q^{2}\right)$, used as a criterion to measure the dependent constructs' predictive relevance. A blindfolding process was used for the calculation. This process omits part of the data for a given construct during parameter estimation and then an attempt is made to estimate what has been omitted using said parameters [179]. The $Q^{2}$ values used to calculate the model's predictive relevance are all above 0 , which is evidence of the path model's predictive relevance and suitable fit $[183,184]$.

The analysis of the path coefficients $(\beta)$ and their statistical significances enables the proposed research hypotheses to be tested. These coefficients measure the degree to which the predicting variables contribute to the endogenous variables' explained variances. Variance in an endogenous construct explained by another latent variable can be measured from the absolute value of multiplying its $\beta$ by the correlation coefficient of the two variables [182]. $\beta$ values between 0.1 and 0.2 could be considered to have moderate influence, although it is desirable for them to be above 0.2 [179].

Also, Falk and Miller [182] propose that a predicting variable should explain at least $1.5 \%$ variance in an endogenous variable. Thus, these authors' empirical rule, rather than setting a minimum value for the coefficient, implies that the product of $\beta$ multiplied by the correlation coefficient between the two variables should be equal to or greater than 0.015 .

Whatever the case, calculation of path coefficients should be accompanied by some measure that reports their statistical significance. Goodness of fit is measured from the $t$ statistic that comes from applying the bootstrap resample method. One-tailed testing has been used in most contrasts as the direction of the relationships is specified in the model [185, 186].

On this basis, the following values are used as statistical significance benchmarks: $t=1.645$ for $95 \%$ confidence, $t=$ 2.327 for $99 \%$, and $t=3.092$ for $99.9 \%$.

Two-tailed testing was used in hypotheses $\mathrm{H}_{17}$ and $\mathrm{H}_{18}$ which are not directional. The acceptance $t$-values for twotailed tests are 1.96, 2.577, and 3.292 at the significance levels of $0.05,0.01$, and 0.001 .

The values obtained in these tests and the standard regression coefficients are given in Table 7 and enable testing of the proposed structural model's hypotheses. As can be observed, statistical significance is obtained in structural paths and in most cases for a $p$-level of 0.001 .
An analysis of Table 7 shows that 12 of the 16 hypotheses are supported. To the contrary, $\mathrm{H}_{8}, \mathrm{H}_{9}, \mathrm{H}_{13}$, and $\mathrm{H}_{14}$ are not supported. Results of the analysis including standardized path coefficients and significances are presented in Figure 2.

With respect to the $\beta$ path coefficient values, when hypotheses are supported, the above- mentioned conditions set by Chin [179] are always complied with. In four cases the influence can be considered to be more moderate but statistically significant: "TMS $\rightarrow$ PEOU” $(\beta=0.181 ; p<0.01)$, “T $\rightarrow$ PU” $(\beta=0.192 ; p<0.01)$, "OS $\rightarrow$ BIU” $(\beta=0.198$; $p<0.01)$, and "TC $\rightarrow$ BIU" $(\beta=-0.164 ; p<0.01)$. At the opposite extreme, the strength of some of the model's relationships stands out, with high path coefficients and $t$ statistics, including “TMS $\rightarrow$ CO” $(\beta=0.455 ; p<0.001)$, "PEOU $\rightarrow$ ATU" $(\beta=0.506 ; p<0.001)$, and "PEOU $\rightarrow$ PU" $(\beta=0.505 ; p<0.001)$.

Changes in $R^{2}$ when a specific exogenous variable is omitted are used to assess a substantial impact on an endogenous construct. This measure is called the $f^{2}$ size effect [2] and values of $0.02,0.15$, and 0.35 represent small, medium, and large effects, respectively [187]. Table 8 summarizes the f square values with their corresponding $p$ values and effect sizes.

\section{Discussion}

Regarding Hypothesis $\mathrm{H}_{1}$, PEOU is confirmed to have a direct influence on PU. Also, both PEOU and PU have a significant influence on ATU $\left(\mathrm{H}_{2}\right.$ and $\left.\mathrm{H}_{3}\right)$. This means that, for cloud providers to induce more organizations to adopt and use cloud computing, they have to offer a supply of products and services based on ease of use and usefulness. In other words, the services should be easy for any user with a minimum user level computer training to use. At the same time, they have to be a useful tool for doing work within the organization and enable tasks to be carried out more quickly at the same time that they improve task performance and boost productivity. The influence of $\mathrm{PU}$ on $\mathrm{BIU}\left(\mathrm{H}_{4}\right)$ is also confirmed, revealing that companies obtain a greater perception of usefulness with cloud computing than they do using services installed on their own computers, local network, or simply the Internet. Effect sizes $\left(f^{2}\right)$ are medium to large in these four relationships.

With respect to $\mathrm{H}_{5}$, results show that ATU has a positive effect on BIU. This confirms the results of prior studies in the information systems area [50,188-190] and in the sphere of cloud computing [84]. When the indicators used to measure ATU (see Table 1) are taken into account, the analyzed organizations consider that the cloud system enables data to be accessed appropriately and provides opportune, reliable information and is perceived as a better technology than the information system used previously. These positive attitudes toward cloud computing are significantly influenced by $\mathrm{PU}$ and PEOU, as seen previously. The two variables enable $R^{2}$ of 66.9\% to be obtained in ATS.

The analysis confirms that TMS has a positive effect on cloud system communication $\left(\mathrm{H}_{6}\right)$ with a medium to large effect size. Also, although being less intensely than in the previous case, TMS is also confirmed to have a direct effect 
TABLE 7: Path coefficients $(\beta)$ and statistical significance $(t)$.

\begin{tabular}{|c|c|c|c|c|}
\hline Number & Hypothesis & $\beta$ (path coefficients) & $T$-value & Supported? \\
\hline $\mathrm{H}_{1}$ & $\mathrm{PEOU} \rightarrow \mathrm{PU}$ & $0.505^{* * *}$ & 4.302 & Yes \\
\hline $\mathrm{H}_{2}$ & $\mathrm{PEOU} \rightarrow \mathrm{ATU}$ & $0.506^{* * *}$ & 6.106 & Yes \\
\hline $\mathrm{H}_{3}$ & $\mathrm{PU} \rightarrow \mathrm{ATU}$ & $0.391^{* * *}$ & 4.560 & Yes \\
\hline $\mathrm{H}_{4}$ & $\mathrm{PU} \rightarrow \mathrm{BIU}$ & $0.470^{* * *}$ & 4.836 & Yes \\
\hline $\mathrm{H}_{5}$ & $\mathrm{ATU} \rightarrow \mathrm{BIU}$ & $0.317^{* *}$ & 3.06 & Yes \\
\hline $\mathrm{H}_{6}$ & $\mathrm{TMS} \rightarrow \mathrm{C}$ & $0.455^{* * *}$ & 5.508 & Yes \\
\hline $\mathrm{H}_{7}$ & $\mathrm{TMS} \rightarrow \mathrm{PEOU}$ & $0.181^{*}$ & 2.107 & Yes \\
\hline $\mathrm{H}_{8}$ & TMS $\rightarrow$ PU & 0.154 & 1.496 & No \\
\hline $\mathrm{H}_{9}$ & $\mathrm{~T} \rightarrow \mathrm{PEOU}$ & 0.056 & 0.77 & No \\
\hline $\mathrm{H}_{10}$ & $\mathrm{~T} \rightarrow \mathrm{C}$ & $0.345^{* * *}$ & 4.414 & Yes \\
\hline $\mathrm{H}_{11}$ & $\mathrm{~T} \rightarrow \mathrm{PU}$ & $0.192^{* *}$ & 2.408 & Yes \\
\hline $\mathrm{H}_{12}$ & $\mathrm{C} \rightarrow \mathrm{PEOU}$ & $0.368^{* * *}$ & 3.949 & Yes \\
\hline $\mathrm{H}_{13}$ & $\mathrm{C} \rightarrow \mathrm{PU}$ & -0.035 & 0.278 & No \\
\hline $\mathrm{H}_{14}$ & $\mathrm{TC} \rightarrow \mathrm{PU}$ & 0.062 & 0.956 & No \\
\hline $\mathrm{H}_{15}$ & $\mathrm{TC} \rightarrow \mathrm{PEOU}$ & $-0.238^{* * *}$ & 3.823 & Yes \\
\hline $\mathrm{H}_{16}$ & $\mathrm{TC} \rightarrow \mathrm{BIU}$ & $-0.164^{* *}$ & 2.452 & Yes \\
\hline $\mathrm{H}_{17}$ & $\mathrm{OS} \rightarrow \mathrm{PU}$ & -0.087 & 0.988 & No \\
\hline $\mathrm{H}_{18}$ & $\mathrm{OS} \rightarrow \mathrm{PEOU}$ & $-0.232^{*}$ & 3.114 & Yes \\
\hline $\mathrm{H}_{19}$ & $\mathrm{OS} \rightarrow \mathrm{BIU}$ & $0.198^{* *}$ & 2.43 & Yes \\
\hline
\end{tabular}

${ }^{*} p<0,05 ;{ }^{* *} p<0,01 ;{ }^{* * *} p<0,001$.

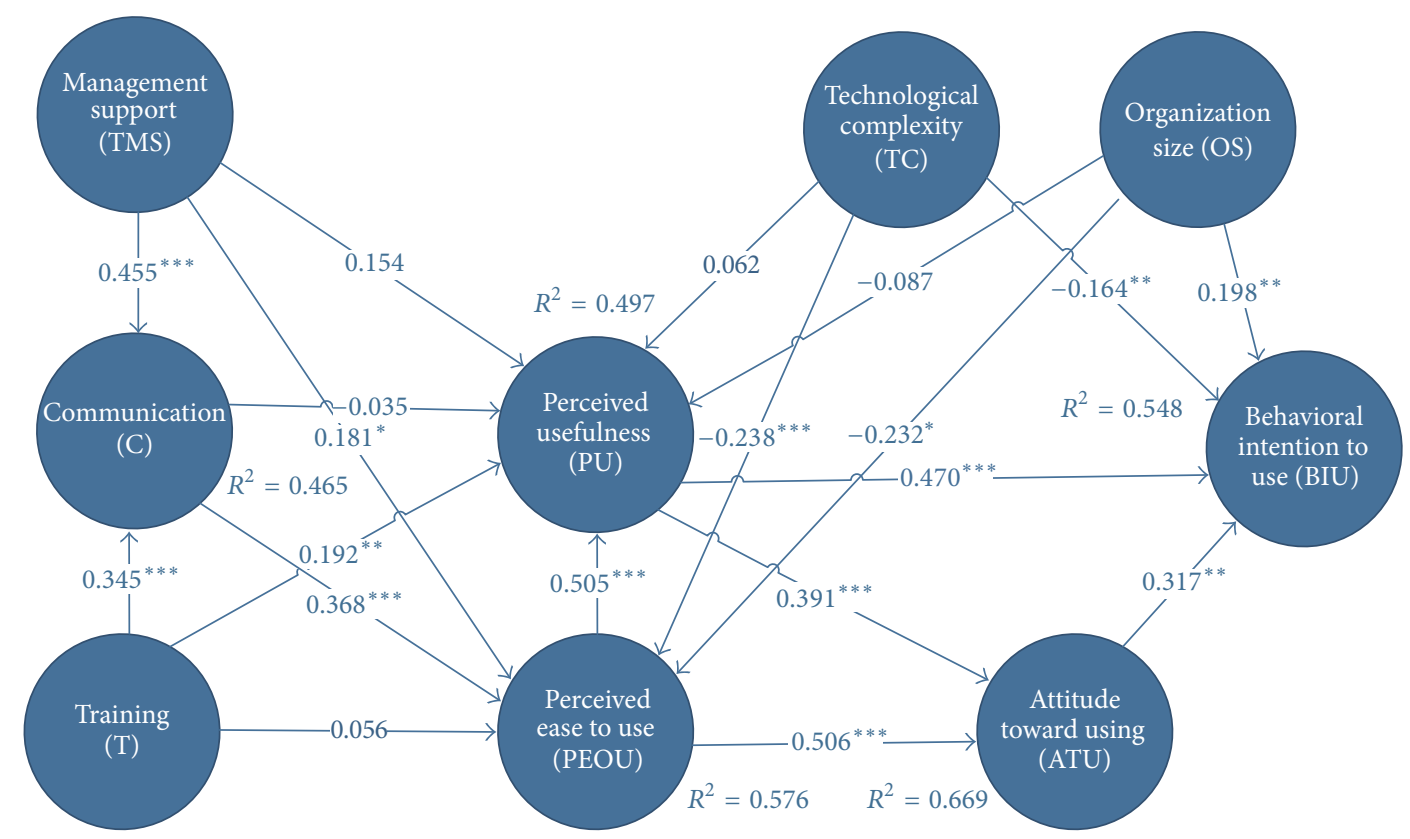

FIGURE 2: PLS results of the structural model with path coefficients.

on PEOU, thus supporting Hypothesis $\mathrm{H}_{7}$. This positive effect enables a similar conclusion to be drawn to prior research on other information systems $[77,136]$ and cloud computing [45].

In other regards, these same prior studies, together with Son et al. [64], led us to presuppose that TMS has an influence on $\mathrm{PU}\left(\mathrm{H}_{8}\right)$. We found a small effect size for this relationship
(Table 8). However, the results do not enable support to be given to this hypothesis and the TMS-PU relationship is not statistically significant. The fact that TMS does not influence PU (or has a very little influence on it) may be due to multiple reasons, such as a change in company strategy priorities as a result of the ongoing economic crisis, or the reticence that cloud computing still arouses due to the fact that the data 
TABLE 8: Theoretical effect sizes for $f^{2}$.

\begin{tabular}{|c|c|c|c|}
\hline Number & Hypothesis & $f^{2}$ & Effect size \\
\hline $\mathrm{H}_{1}$ & $\mathrm{PEOU} \rightarrow \mathrm{PU}$ & 0.218 & Medium \\
\hline $\mathrm{H}_{2}$ & $\mathrm{PEOU} \rightarrow \mathrm{ATU}$ & 0.356 & Large \\
\hline $\mathrm{H}_{3}$ & $\mathrm{PU} \rightarrow \mathrm{ATU}$ & 0.344 & Medium \\
\hline $\mathrm{H}_{4}$ & $\mathrm{PU} \rightarrow \mathrm{BIU}$ & 0.216 & Medium \\
\hline $\mathrm{H}_{5}$ & $\mathrm{ATU} \rightarrow \mathrm{BIU}$ & 0.076 & Small \\
\hline $\mathrm{H}_{6}$ & $\mathrm{TMS} \rightarrow \mathrm{C}$ & 0.324 & Medium \\
\hline $\mathrm{H}_{7}$ & $\mathrm{TMS} \rightarrow \mathrm{PEOU}$ & 0.049 & Small \\
\hline $\mathrm{H}_{8}$ & TMS $\rightarrow$ PU & 0.028 & Small \\
\hline $\mathrm{H}_{9}$ & $\mathrm{~T} \rightarrow \mathrm{PEOU}$ & 0.003 & - \\
\hline $\mathrm{H}_{10}$ & $\mathrm{~T} \rightarrow \mathrm{C}$ & 0.167 & Medium \\
\hline $\mathrm{H}_{11}$ & $\mathrm{~T} \rightarrow \mathrm{PU}$ & 0.048 & Small \\
\hline $\mathrm{H}_{12}$ & $\mathrm{C} \rightarrow \mathrm{PEOU}$ & 0.160 & Medium \\
\hline $\mathrm{H}_{13}$ & $\mathrm{C} \rightarrow \mathrm{PU}$ & 0.001 & - \\
\hline $\mathrm{H}_{14}$ & $\mathrm{TC} \rightarrow \mathrm{PU}$ & 0.006 & - \\
\hline $\mathrm{H}_{15}$ & $\mathrm{TC} \rightarrow \mathrm{PEOU}$ & 0.121 & Small \\
\hline $\mathrm{H}_{16}$ & $\mathrm{TC} \rightarrow \mathrm{BIU}$ & 0.064 & Small \\
\hline $\mathrm{H}_{17}$ & $\mathrm{OS} \rightarrow \mathrm{PU}$ & 0.012 & - \\
\hline $\mathrm{H}_{18}$ & $\mathrm{OS} \rightarrow \mathrm{PEOU}$ & 0.110 & Small \\
\hline $\mathrm{H}_{19}$ & $\mathrm{OS} \rightarrow \mathrm{BIU}$ & 0.070 & Small \\
\hline
\end{tabular}

are physically held outside the organization, sometimes even in other countries with lax legislation on data protection, intellectual property, copyrights, and so forth.

With regard to hypothesis $\mathrm{H}_{9}$, the training-PEOU relationship has not been supported in the present research and, consequently, the conclusions drawn in prior studies $[45,50,52,140]$ are not backed up. This does not mean that training has not been well scored by organizations. In fact, the four items used to measure this variable all had high averages, in the responses both from top management and from technical nonmanagement personnel. Furthermore, as will be seen below, its influence on PU is significant, as said previous studies confirm.

The results also show a significant relationship between training and communication $\left(\mathrm{H}_{10}\right)$. This confirms that companies' training programs helped to make communication about cloud computing and any obstacles that their implementation might entail more fluid. This relationship can also be placed in a context in which shared knowledge-related training and Web 2.0 communication often represent the key to extending innovation adoption. The skills of the ICT sector professionals are a core factor that needs to be taken into account and, as a result, their ongoing training and skill enhancement are a major challenge [191, 192], with the socalled Web 2.0 being an extremely important source.

The confirmation of hypothesis $\mathrm{H}_{11}$ corroborates prior studies on the influence of training on PU $[45,51,52,76]$, confirming that appropriate training improves organizations' perception of the advantages that cloud systems bring about in their workers' performance.

Meanwhile, hypothesis $\mathrm{H}_{12}$ is confirmed with a high level of significance and communication is presented as one of the most important of the variables external to the traditional TAM model. The results are therefore similar to those of other prior studies $[49,52,140]$. However, the results for hypothesis $\mathrm{H}_{13}$ do not allow the statement that communication is perceived as a factor that influences this technology's perception of utility in the analyzed organizations. Therefore, organizations seem to give greater importance to the role of communication in reducing the risk of confusion and the effort that cloud system use entails, rather than its role as a factor that improves perception of the degree to which systems improve work performance within the organization.

Focusing on the influence of technological complexity, the first of the hypotheses relating to this variable $\left(\mathrm{H}_{14}\right)$ did not receive support. The complexity of cloud systems therefore does not seem to affect the advantages that companies perceive that they provide. In fact, in aggregated terms, the surveyed companies do not perceive cloud computing as an especially complex technology. This result contradicts the Gangwar et al. [45] conclusions, the only study on cloud computing adoption detected with respect to the CTPU relationship. To the contrary, testing hypothesis $\mathrm{H}_{15}$ enabled it to be concluded that TC does have a negative effect on PEOU. This is in line with Bueno and Salmerón [50], Son et al. [64], Rajan and Baral [76], and Gangwar et al. [45]. Despite the relationship not being very strong, hypothesis $\mathrm{H}_{16}$ is also supported, thus confirming that $\mathrm{TC}$ is negatively linked with BIU. This last result coincides with the conclusions obtained by Tsai et al. [124] and, in the specific cloud computing sphere, Oliveira et al. [11]. This implies that although organizations perceive cloud systems to be useful and easy to use, their implementation can entail certain problems that some companies find difficult to contend with technologically, such as the need for ICT specialists or process and data protection requirements.

Finally, the last group of hypotheses analyzes whether the adoption of cloud computing bears any relationship with the size of the organization, measured by turnover and number of employees. With respect to hypothesis $\mathrm{H}_{17}$, the results of the present study do not show any significant influence on PU. To the contrary, significant relationships are found between $\mathrm{OS}$ and PEOU $\left(\mathrm{H}_{18}\right)$ and between OS and $\mathrm{BIU}\left(\mathrm{H}_{19}\right)$. With respect to PEOU, this relationship is inverse, which leads us to state that the efforts required to adopt cloud systems are perceived to be greater in larger companies than in those smaller in size. This could be due to the greater complexity of innovation projects undertaken by these companies, which leads them to perceive greater difficulties and possible eventualities after cloud computing adoption. With regard to BIU, the results of prior studies are confirmed in the sphere of cloud computing [11, 109], as they also show a direct OS-BIU relationship. An organization's size therefore has a significant influence on the speed and ease with which organizations can incorporate cloud computing and it is the largest companies that demonstrate greater innovation.

\section{Conclusion}

Cloud computing technology is one of the most important Internet developments and represents an essential step forward for information systems. However, for organizations especially, the adoption process is neither easy nor quick and 
depends on a large number of determinants that the present study seeks to identify.

Based on TAM and a number of external variables, the model proposed in this research was developed after analyzing a range of frameworks and theories used in different studies on technology acceptance in the sphere of information systems. The model was empirically assessed using a sample of 150 organizations in the Andalusia region (Spain).

In general terms, the original PU, PEOU, and ATU-based TAM model tends to explain about $40 \%$ of system intention of use [66]. It is recommended that the model be extended by the inclusion of other variables in order to increase its predictive capacity. In our study, extending the model in this way has enabled $54.8 \% R^{2}$ to be achieved in behavioral intention to use. To be precise, the five external variables that were considered to be especially interesting and which have enabled a satisfactory degree of fit to be obtained are top management support, communication, organization size, training, and technological complexity.

The results indicate that the analyzed external variables have a direct or indirect influence on final intention of use of cloud computing. These results complement the literature that assesses cloud system adoption in organizations and contribute new determinants. First, the application of the TAM model in this field is validated and the five corresponding hypotheses are supported. Second, organization size and technological complexity are proven to have a direct influence on final adoption of cloud technology. Lastly, all the external variables except for training are demonstrated to have an indirect influence on cloud computing adoption via perceived ease of use, with training exerting influence via perceived usefulness. Our study therefore suggests that perceived ease of use is a better mediating variable for the model's external variables than perceived usefulness, on which it also exerts a very significant influence. Be that as it may, as an integral part of TAM, the influence of perceived usefulness on behavioral intention to use and attitude toward using is clear.

\section{Limitations of the Study and Future Lines of Research}

It should be borne in mind that all the results of this research have been obtained from a sample of companies located in Andalusia (Spain). If the number of surveyed organizations and the analytical methodology followed are taken into account, the conclusions can be stated to reliably reflect the situation of cloud computing in said region, with its own particular socioeconomic circumstances. Therefore, the corresponding caution should be shown when extrapolating the results to other countries or regions, and aspects such as the current deployment of high speed broadband, prices, the number of existing micro companies, and GDP should be taken into account.

Among the future lines of research that we propose are expanding the study to a sample of a greater number of companies and organizations in other areas, including other countries, with a differentiation made between the development steps with respect to cloud technology and the cultural or technological context, and the PaaS deployment model, which is especially important in the ICT sector. It would also be especially interesting to continue the study of the factors that impact cloud computing adoption by including aspects such as the time of adoption and deployment and company cooperation, assessing the effects that involvement in company networks designed to drive up organizational training and the standardization of interfaces or technological platforms have. In addition, a more detailed study could be made of aspects relating to trust in the cloud system as even though the items included in the ATU variable in the present research include general aspects relating to organizations' perceptions of risk, the analysis of sources of risk could be the object of a deeper examination. Specifically, it would be especially interesting to analyze the influence of service outages, incompliance with agreements, the effectiveness of security devices, data loss, and improper data use.

\section{Conflicts of Interest}

The authors declare that there are no conflicts of interest regarding the publication of this paper.

\section{References}

[1] R. Rezaei, T. K. Chiew, S. P. Lee, and Z. Shams Aliee, "A semantic interoperability framework for software as a service systems in cloud computing environments," Expert Systems with Applications, vol. 41, no. 13, pp. 5751-5770, 2014.

[2] W. L. Shiau and P. Y. K. Chau, "Understanding behavioral intention to use a cloud computing classroom: A multiple model comparison approach," Information Management, vol. 53, pp. 355-365, 2016.

[3] T. Dillon, C. Wu, and E. Chang, "Cloud computing: issues and challenges," in Proceedings of the 24th IEEE International Conference on Advanced Information Networking and Applications (AINA '10), pp. 27-33, Perth, Australia, April 2010.

[4] M. Fan, S. Kumar, and A. B. Whinston, "Short-term and longterm competition between providers of shrink-wrap software and software as a service," European Journal of Operational Research, vol. 196, no. 2, pp. 661-671, 2009.

[5] N. A. Sultan, "Reaching for the "cloud": How SMEs can manage," International Journal of Information Management, vol. 31, no. 3, pp. 272-278, 2011.

[6] M. Armbrust, A. Fox, R. Griffith et al., "A view of cloud computing," Communications of the ACM, vol. 53, no. 4, pp. 50$58,2010$.

[7] S. U. R. Malik, S. U. Khan, S. J. Ewen et al., "Performance analysis of data intensive cloud systems based on data management and replication: a survey," Distributed and Parallel Databases, vol. 34, no. 2, pp. 179-215, 2016.

[8] S. Haag and A. Eckhardt, "Organizational cloud service adoption: a scientometric and content-based literature analysis," Journal of Business Economics, vol. 84, no. 3, pp. 407-440, 2014.

[9] A. Benlian, M. Koufaris, and T. Hess, "Service quality in software-as-a-service: Developing the SaaS-Qual measure and examining its role in usage continuance," Journal of Management Information Systems, vol. 28, no. 3, pp. 85-126, 2011. 
[10] R. Buyya, C. S. Yeo, S. Venugopal, J. Broberg, and I. Brandic, "Cloud computing and emerging IT platforms: vision, hype, and reality for delivering computing as the 5th utility," Future Generation Computer Systems, vol. 25, no. 6, pp. 599-616, 2009.

[11] T. Oliveira, M. Thomas, and M. Espadanal, "Assessing the determinants of cloud computing adoption: an analysis of the manufacturing and services sectors," Information and Management, vol. 51, no. 5, pp. 497-510, 2014.

[12] V. Ratten, "Continuance use intention of cloud computing: Innovativeness and creativity perspectives," Journal of Business Research, vol. 69, no. 5, pp. 1737-1740, 2016.

[13] G. Garrison, S. Kim, and R. L. Wakefield, "Success factors for deploying cloud computing," Communications of the ACM, vol. 55, no. 9, pp. 62-68, 2012.

[14] A. Duncan, S. Creese, and M. Goldsmith, "An overview of insider attacks in cloud computing," Concurrency Computation, vol. 27, no. 12, pp. 2964-2981, 2015.

[15] M. Ali, S. U. Khan, and A. V. Vasilakos, "Security in cloud computing: opportunities and challenges," Information Sciences. An International Journal, vol. 305, pp. 357-383, 2015.

[16] J. M. Del Alamo, R. Trapero, Y. S. Martin, J. C. Yelmo, and N. Suri, "Assessing privacy capabilities of cloud service providers," IEEE Latin America Transactions, vol. 13, no. 11, pp. 3634-3641, 2015.

[17] C. W. Autry, S. J. Grawe, P. J. Daugherty, and R. G. Richey, “The effects of technological turbulence and breadth on supply chain technology acceptance and adoption," Journal of Operations Management, vol. 28, no. 6, pp. 522-536, 2010.

[18] N. Phaphoom, X. Wang, S. Samuel, S. Helmer, and P. Abrahamsson, "A survey study on major technical barriers affecting the decision to adopt cloud services," Journal of Systems and Software, vol. 103, pp. 167-181, 2015.

[19] A. Abdollahzadehgan, M. M. Gohary, A. R. C. Hussin, and M. Amini, "The organizational critical success factors for adopting cloud computing in SMEs," Journal of Information Systems Research and Innovation, vol. 4, no. 1, pp. 67-74, 2013.

[20] T. Brandt, Y. Tian, M. Hedwig, and D. Neumann, "Autonomic management of Software as a Service systems with multiple quality of service classes," in Proceedings of the 20th European Conference on Information Systems, (ECIS'12), Barcelona, Spain, June 2012.

[21] J. Li, B. Li, T. Wo et al., "CyberGuarder: a virtualization security assurance architecture for green cloud computing," Future Generation Computer Systems, vol. 28, no. 2, pp. 379-390, 2012.

[22] J. Spillner, G. Bombach, S. Matthischke, J. Müller, R. Tzschichholz, and A. Schill, "Information dispersion over redundant arrays of optimal cloud storage for desktop users," in Proceedings of the 4th IEEE/ACM International Conference on Cloud and Utility Computing, (UCC'11), pp. 1-8, Melbourne, Australia, December 2011.

[23] Q.-A. Wang, C. Wang, K. Ren, W.-J. Lou, and J. Li, "Enabling public auditability and data dynamics for storage security in cloud computing," IEEE Transactions on Parallel and Distributed Systems, vol. 22, no. 5, pp. 847-859, 2011.

[24] C. Wang, S. S. Chow, Q. Wang, K. Ren, and W. Lou, "Privacypreserving public auditing for secure cloud storage," IEEE Transactions on Computers, vol. 62, no. 2, pp. 362-375, 2013.

[25] Q. Wang, C. Wang, K. Ren, W. Lou, and J. Li, "Enabling public auditability and data dynamics for storage security in cloud computing," IEEE Transactions on Parallel and Distributed Systems, vol. 22, no. 5, pp. 847-859, 2011.
[26] G. Chen, Y. Wu, J. Liu, G. Yang, and W. Zheng, "Optimization of sub-query processing in distributed data integration systems," Journal of Network and Computer Applications, vol. 34, no. 4, pp. 1035-1042, 2011.

[27] R. L. Grossman, Y. Gu, M. Sabala, and W. Zhang, "Compute and storage clouds using wide area high performance networks," Future Generation Computer Systems, vol. 25, no. 2, pp. 179-183, 2009.

[28] M. Abu Sharkh, A. Kanso, A. Shami, and P. Öhlén, "Building a cloud on earth: A study of cloud computing data center simulators," Computer Networks, vol. 108, pp. 78-96, 2016.

[29] A. Iosup, S. Ostermann, N. Yigitbasi, R. Prodan, T. Fahringer, and D. Epema, "Performance analysis of cloud computing services for many-tasks scientific computing," IEEE Transactions on Parallel and Distributed Systems, vol. 22, no. 6, pp. 931-945, 2011.

[30] A. Lin and N.-C. Chen, "Cloud computing as an innovation: Percepetion, attitude, and adoption," International Journal of Information Management, vol. 32, no. 6, pp. 533-540, 2012.

[31] G. Feuerlicht and S. Govardhan, "Impact of cloud computing: beyond a technology trend," in Proceedings of The International Conference on Systems Integration, Oeconomica, vol. 1, p. 8, Prague, Czech Republic, 2010.

[32] G. Feuerlicht, L. Burkon, and M. Sebesta, "Cloud computing adoption: what are the issues?" System Integration, vol. 18, no. 2, pp. 187-192, 2011.

[33] P. Géczy, N. Izumi, and H. Kôiti, "Cloudsourcing: managing cloud adoption," Global Journal of Business Research, vol. 6, no. 2, pp. 57-70, 2012.

[34] T. Ackermann, A. Benlian, T. Widjaja, and P. Buxmann, "Perceived IT security risks of cloud computing: conceptualization and scale development," in Proceedings of the International Conference on Information Systems, (ICIS'12), pp. 3468-3487, Orlando, Fla, USA, December 2012.

[35] A. Benlian and T. Hess, "Opportunities and risks of softwareas-a-service: findings from a survey of IT executives," Decision Support Systems, vol. 52, no. 1, pp. 232-246, 2011.

[36] B. Martens and F. Teuteberg, "Risk and compliance management for cloud computing services: designing a reference model," in Proceedings of the 17th Americas Conference on Information Systems 2011, (AMCIS'11), pp. 2041-2050, Detroit, Mich, USA, August 2011.

[37] D. Yuan, Y. Yang, X. Liu, and J. Chen, “On-demand minimum cost benchmarking for intermediate dataset storage in scientific cloud workflow systems," Journal of Parallel and Distributed Computing, vol. 71, no. 2, pp. 316-332, 2011.

[38] W. Pauley, "Cloud provider transparency: An empirical evaluation," IEEE Security and Privacy, vol. 8, no. 6, pp. 32-39, 2010.

[39] Y.-M. Wang, Y.-S. Wang, and Y.-F. Yang, "Understanding the determinants of RFID adoption in the manufacturing industry," Technological Forecasting and Social Change, vol. 77, no. 5, pp. 803-815, 2010.

[40] I. Ion, N. Sachdeva, P. Kumaraguru, and S. Čapkun, "Home is safer than the cloud! Privacy concerns for consumer cloud storage," in Proceedings of the 7th Symposium on Usable Privacy and Security, (SOUPS'11), Pittsburgh, Pa, USA, July 2011.

[41] S. Pearson, “Toward accountability in the cloud," IEEE Internet Computing, vol. 15, no. 4, pp. 64-69, 2011.

[42] M. D. Ryan, "Viewpoint cloud computing privacy concerns on our doorstep," Communications of the ACM, vol. 54, no. 1, pp. 36-38, 2011. 
[43] M. Walterbusch, B. Martens, and F. Teuteberg, "Evaluating cloud computing services from a total cost of ownership perspective," Management Research Review, vol. 36, no. 6, pp. 613-638, 2013.

[44] S. Singh, Y. Jeong, and J. H. Park, "A survey on cloud computing security: Issues, threats, and solutions," Journal of Network and Computer Applications, vol. 75, pp. 200-222, 2016.

[45] H. Gangwar, H. Date, and R. Ramaswamy, "Understanding determinants of cloud computing adoption using an integrated TAM-TOE model," Journal of Enterprise Information Management, vol. 28, no. 1, pp. 107-130, 2015.

[46] V. Venkatesh and F. D. Davis, "A theoretical extension of the technology acceptance model: four longitudinal field studies," Management Science, vol. 46, no. 2, pp. 186-204, 2000.

[47] W.-W. Wu, "Developing an explorative model for SaaS adoption," Expert Systems with Applications, vol. 38, no. 12, pp. 1505715064, 2011.

[48] D. Burda and F. Teuteberg, "The role of trust and risk perceptions in cloud archiving - Results from an empirical study," Journal of High Technology Management Research, vol. 25, no. 2, pp. 172-187, 2014.

[49] K. Amoako-Gyampah and A. F. Salam, "An extension of the technology acceptance model in an ERP implementation environment," Information and Management, vol. 41, no. 6, pp. 731$745,2004$.

[50] S. Bueno and J. L. Salmeron, "TAM-based success modeling in ERP," Interacting with Computers, vol. 20, no. 6, pp. 515-523, 2008.

[51] M. Dolores Gallego, S. Bueno, F. José Racero, and J. Noyes, "Open source software: The effects of training on acceptance," Computers in Human Behavior, vol. 49, pp. 390-399, 2015.

[52] D. Lee, S. M. Lee, D. L. Olson, and S. H. Chung, "The effect of organizational support on ERP implementation," Industrial Management and Data Systems, vol. 110, no. 2, pp. 269-283, 2010.

[53] M. K. Chang and W. Cheung, "Determinants of the intention to use Internet/WWW at work: A confirmatory study," Information and Management, vol. 39, no. 1, pp. 1-14, 2001.

[54] C. M. Messerschmidt and O. Hinz, "Explaining the adoption of grid computing: An integrated institutional theory and organizational capability approach," Journal of Strategic Information Systems, vol. 22, no. 2, pp. 137-156, 2013.

[55] B. Ramdani, P. Kawalek, and O. Lorenzo, "Predicting SMEs' adoption of enterprise systems," Journal of Enterprise Information Management, vol. 22, no. 1, pp. 10-24, 2009.

[56] N. Oly Ndubisi and M. Jantan, "Evaluating IS usage in Malaysian small and medium-sized firms using the technology acceptance model," Logistics Information Management, vol. 16, no. 6, pp. 440-450, 2003.

[57] M. Fishbein and I. Ajzen, Belief, Attitude Intention, and Behavior: An Introduction to Theory and Research, Addison-Wesley, Reading, Mass, USA, 1975.

[58] I. Ajzen, From Intentions to Actions: A Theory of Planned Behavior, Springer, Berlin, Germany, 1985.

[59] F. D. Davis, "Perceived usefulness, perceived ease of use, and user acceptance of information technology," MIS Quarterly, vol. 13, no. 3, pp. 319-339, 1989.

[60] Y. Au and H. Zafar, A Multi-Country Assessment of Mobile Payment Adoption, Working Paper Series No. 0055IS-296-2008. College of Business, College of Business, University of Texas, San Antonio, Tex, USA, 2008.
[61] L.-D. Chen and J. Tan, "Technology adaptation in E-commerce: key determinants of virtual stores acceptance," European Management Journal, vol. 22, no. 1, pp. 74-86, 2004.

[62] R. Cheung and D. Vogel, "Predicting user acceptance of collaborative technologies: an extension of the technology acceptance model for e-learning," Computers and Education, vol. 63, pp. 160-175, 2013.

[63] J. Joo and Y. Sang, "Exploring Koreans' smartphone usage: An integrated model of the technology acceptance model and uses and gratifications theory," Computers in Human Behavior, vol. 29, no. 6, pp. 2512-2518, 2013.

[64] H. Son, Y. Park, C. Kim, and J.-S. Chou, "Toward an understanding of construction professionals' acceptance of mobile computing devices in South Korea: An extension of the technology acceptance model," Automation in Construction, vol. 28, pp. 8290, 2012.

[65] D. Gefen, E. Karahanna, and D. W. Straub, "Trust and tam in online shopping: an integrated model," MIS Quarterly: Management Information Systems, vol. 27, no. 1, pp. 51-90, 2003.

[66] P. Legris, J. Ingham, and P. Collerette, "Why do people use information technology? A critical review of the technology acceptance model," Information \& Management, vol. 40, no. 3, pp. 191-204, 2003.

[67] S. Hong, J. Y. L. Thong, and K. Y. Tam, "Understanding continued information technology usage behavior: a comparison of three models in the context of mobile internet," Decision Support Systems, vol. 42, no. 3, pp. 1819-1834, 2006.

[68] V. Venkatesh and H. Bala, “Technology acceptance model 3 and a research agenda on interventions," Decision Sciences, vol. 39, no. 2, pp. 273-315, 2008.

[69] V. Venkatesh, M. G. Morris, G. B. Davis, and F. D. Davis, "User acceptance of information technology: toward a unified view," MIS Quarterly: Management Information Systems, vol. 27, no. 3, pp. 425-478, 2003.

[70] S. Gao, J. Krogstie, and K. Siau, "Adoption of mobile information services: an empirical study," Mobile Information Systems, vol. 10, no. 2, pp. 147-171, 2014.

[71] B. H. Wixom and P. A. Todd, "A theoretical integration of user satisfaction and technology acceptance," Information Systems Research, vol. 16, no. 1, pp. 85-102, 2005.

[72] J. Bradley and C. C. Lee, "ERP training and user satisfaction: a case study," International Journal of Enterprise Information Systems, vol. 3, no. 4, pp. 33-50, 2007.

[73] F. Calisir, C. Altin Gumussoy, and A. Bayram, "Predicting the behavioral intention to use enterprise resource planning systems: an exploratory extension of the technology acceptance model," Management Research News, vol. 32, no. 7, pp. 597-613, 2009.

[74] K.-Y. Kwahk and J.-N. Lee, “The role of readiness for change in ERP implementation: theoretical bases and empirical validation," Information and Management, vol. 45, no. 7, pp. 474-481, 2008.

[75] M. Mayeh, T. Ramayah, and A. Mishra, "The role of absorptive capacity, communication and trust in ERP adoption," Journal of Systems and Software, vol. 119, pp. 58-69, 2016.

[76] C. A. Rajan and R. Baral, "Adoption of ERP system: An empirical study of factors influencing the usage of ERP and its impact on end user," IIMB Management Review, vol. 27, no. 2, pp. 105-117, 2015.

[77] Y.-Y. Shih and S.-S. Huang, "The actual usage of ERP systems: an extended technology acceptance perspective," Journal of 
Research and Practice in Information Technology, vol. 41, no. 3, pp. 263-276, 2009.

[78] S. L. Shivers-Blackwell and A. C. Charles, "Ready, set, go: Examining student readiness to use ERP technology," Journal of Management Development, vol. 25, no. 8, pp. 795-805, 2006.

[79] S. Sternad and S. Bobek, "Impacts of TAM-based external factors on ERP acceptance," Procedia Technology, vol. 9, pp. 3342, 2013.

[80] Y. Sun, A. Bhattacherjee, and Q. Ma, "Extending technology usage to work settings: The role of perceived work compatibility in ERP implementation," Information and Management, vol. 46, no. 6, pp. 351-356, 2009.

[81] F.-M. E. Uzoka, R. O. Abiola, and R. Nyangeresi, "Influence of product and organizational constructs on ERP acquisition using an extended technology acceptance model," International Journal of Enterprise Information Systems, vol. 4, no. 2, pp. 6784, 2008.

[82] E. Youngberg, D. Olsen, and K. Hauser, "Determinants of professionally autonomous end user acceptance in an enterprise resource planning system environment," International Journal of Information Management, vol. 29, no. 2, pp. 138-144, 2009.

[83] S. Agrebi and J. Jallais, "Explain the intention to use smartphones for mobile shopping," Journal of Retailing and Consumer Services, vol. 22, pp. 16-23, 2015.

[84] J.-C. Hong, M.-Y. Hwang, H.-F. Hsu, W.-T. Wong, and M.-Y. Chen, "Applying the technology acceptance model in a study of the factors affecting usage of the Taiwan digital archives system," Computers and Education, vol. 57, no. 3, pp. 2086-2094, 2011.

[85] H. S. Yoon and L. M. Barker Steege, "Development of a quantitative model of the impact of customers' personality and perceptions on Internet banking use," Computers in Human Behavior, vol. 29, no. 3, pp. 1133-1141, 2013.

[86] H. Chen, W. Rong, X. Ma, Y. Qu, and Z. Xiong, An extended technology acceptance model for mobile social gaming service popularity analysis, Mobile Information Systems, 2017.

[87] R. A. Sánchez and A. D. Hueros, "Motivational factors that influence the acceptance of Moodle using TAM," Computers in Human Behavior, vol. 26, no. 6, pp. 1632-1640, 2010.

[88] D. Y. Lee and M. R. Lehto, "User acceptance of YouTube for procedural learning: An extension of the Technology Acceptance Model," Computers and Education, vol. 61, no. 1, pp. 193-208, 2013.

[89] Y.-W. Liao, Y.-M. Huang, H.-C. Chen, and S.-H. Huang, "Exploring the antecedents of collaborative learning performance over social networking sites in a ubiquitous learning context," Computers in Human Behavior, vol. 43, pp. 313-323, 2015.

[90] A. Tarhini, K. Hone, and X. Liu, "The effects of individual differences on e-learning users' behaviour in developing countries: A structural equation model," Computers in Human Behavior, vol. 41, pp. 153-163, 2014.

[91] L. Tornatzky and M. Fleischer, The Process of Technology Innovation, Lexington Books, Lexington, Mass, USA, 1990.

[92] J. Baker, "The technology-organization-environment framework," in Information Systems Theory, vol. 28 of Integrated Series in Information Systems, pp. 231-245, Springer, New York, NY, USA, 2012.

[93] K. Zhu, K. Kraemer, S. Xu, and J. Dedrick, "Information technology payoff in E-Business environments: An international perspective on value creation of E-Business in the financial services industry," Journal of Management Information Systems, vol. 21, no. 1, pp. 17-54, 2004.
[94] H.-F. Lin and S.-M. Lin, "Determinants of e-business diffusion: A test of the technology diffusion perspective," Technovation, vol. 28, no. 3, pp. 135-145, 2008.

[95] M. I. Salwani, G. Marthandan, M. D. Norzaidi, and S. C. Chong, "E-commerce usage and business performance in the Malaysian tourism sector: empirical analysis," Information Management and Computer Security, vol. 17, no. 2, pp. 166-185, 2009.

[96] A. Y. L. Chong, N. Darmawan, K. B. Ooi, and V. H. Lee, "Determinants of 3G adoption in Malaysia: A structural analysis," Journal of Computer Information Systems, vol. 51, pp. 71-80, 2011.

[97] M. Ghobakhloo, M. S. Sabouri, S. H. Tang, and N. Zulkifli, "Information technology adoption in small and medium-sized enterprises: an appraisal of two decades literature," Interdisciplinary Journal of Research in Business, vol. 1, pp. 53-80, 2011.

[98] R. Klein, "Assimilation of Internet-based purchasing applications within medical practices," Information and Management, vol. 49, no. 3-4, pp. 135-141, 2012.

[99] M. Liu, "Wireless communications, networking and mobile computing," in Proceedings of the 4th International Conference, (WiCOM'08), pp. 12-14, 2008.

[100] A. Scupola, "The adoption of internet commerce by SMEs in the South of Italy: an environmental, technological and organizational perspective," Journal of Global Information Technology Management, vol. 6, no. 1, pp. 52-71, 2014.

[101] A. Seyal, M. M. Awais, S. Shamail, and A. Abbas, "Determinants of electronic commerce in Pakistan: preliminary evidence from small and medium enterprises," Electronic Markets, vol. 14, no. 4, pp. 372-387, 2004.

[102] K. Zhu, K. L. Kraemer, and S. Xu, “The process of innovation assimilation by firms in different countries: A technology diffusion perspective on e-business," Management Science, vol. 52, no. 10, pp. 1557-1576, 2006.

[103] T. Oliveira and M. Martins, "A comparison of web site adoption in small and large Portuguese firms," in Proceedings of the International Conference on e-Business, Porto, Portugal, 2008.

[104] S. S. Alam, "Adoption of internet in Malaysian SMEs," Journal of Small Business and Enterprise Development, vol. 16, no. 2, pp. 240-255, 2009.

[105] M. Tan and T. S. H. Teo, "Factors influencing the adoption of the internet," International Journal of Electronic Commerce, vol. 2, no. 3, pp. 5-18, 1998.

[106] E. M. Rogers, Diffusion of Innovations, Free Press, New York, NY, USA, 4th edition, 1995.

[107] P.-F. Hsu, S. Ray, and Y.-Y. Li-Hsieh, "Examining cloud computing adoption intention, pricing mechanism, and deployment model," International Journal of Information Management, vol. 34, no. 4, pp. 474-488, 2014.

[108] Y. H. Li, "An empirical investigation on the determinants of eprocurement adoption in Chinese manufacturing enterprises," in Proceedings of the 15th International Conference on Management Science Engineering (Vols I and II), pp. 32-37, Long Beach, Calif, USA, 2008.

[109] C. Low, Y. Chen, and M. Wu, "Understanding the determinants of cloud computing adoption," Industrial Management and Data Systems, vol. 111, no. 7, pp. 1006-1023, 2011.

[110] A. Bhattacherjee and S. C. Park, "Why end-users move to the cloud: a migration-theoretic analysis," European Journal of Information Systems, vol. 23, no. 3, pp. 357-372, 2014.

[111] A. Giessmann and K. Stanoevska, "Platform as a service: a conjoint study on consumers' preferences," in Proceedings of the International Conference on Information Systems, (ICIS'12), pp. 2800-2819, Orlando, Fla, USA, December 2012. 
[112] T. S. Behrend, E. N. Wiebe, J. E. London, and E. C. Johnson, "Cloud computing adoption and usage in community colleges," Behaviour and Information Technology, vol. 30, no. 2, pp. 231240, 2011.

[113] Y. Wu, C. G. Cegielski, B. T. Hazen, and D. J. Hall, "Cloud computing in support of supply chain information system infrastructure: Understanding when to go to the cloud," Journal of Supply Chain Management, vol. 49, no. 3, pp. 25-41, 2013.

[114] M. Moqbel, V. Bartelt, and M. Al-Suqri, "A study of personal cloud computing: compatibility, social influence, and moderating role of perceived familiarity," in Proceedings of the 20th Americas Conference on Information Systems, (AMCIS'14), Savannah, Ga, USA, August 2014.

[115] S. K. Sharma, A. H. Al-Badi, S. M. Govindaluri, and M. H. Al-Kharusi, "Predicting motivators of cloud computing adoption: A developing country perspective," Computers in Human Behavior, vol. 62, pp. 61-69, 2016.

[116] M. Nkhoma and D. Dang, "Contributing factors of cloud computing adoption: a technology-organisation-environment framework a roach," International Journal of Information Systems and Engineering, vol. 1, no. 1, pp. 38-49.

[117] Y. Alshamaila, S. Papagiannidis, and F. Li, "Cloud computing adoption by SMEs in the north east of England: a multiperspective framework," Journal of Enterprise Information Management, vol. 26, no. 3, pp. 250-275, 2013.

[118] Z. Yang, J. Sun, Y. Zhang, and Y. Wang, "Understanding SaaS adoption from the perspective of organizational users: A tripod readiness model," Computers in Human Behavior, vol. 45, pp. 254-264, 2015.

[119] R. A. Dos Reis and M. Do Carmo Duarte Freitas, "Critical factors on information technology acceptance and use: An analysis on small and medium Brazilian clothing industries," in Proceedings of the 2nd International Conference on Information Technology and Quantitative Management, ITQM 2014, pp. 105114, June 2014.

[120] H. Gangwar, H. Date, and A. D. Raoot, "Review on IT adoption: Insights from recent technologies," Journal of Enterprise Information Management, vol. 27, no. 4, pp. 488-502, 2014.

[121] S. Taylor and P. A. Todd, "Understanding information technology usage: A test of competing models," Information Systems Research, vol. 6, no. 2, pp. 144-176, 1995.

[122] M. H. Shah and F. A. Siddiqui, "Organisational critical success factors in adoption of e-banking at the Woolwich bank," International Journal of Information Management, vol. 26, no. 6, pp. 442-456, 2006.

[123] M. Ghobakhloo, D. Arias-Aranda, and J. Benitez-Amado, "Adoption of e-commerce applications in SMEs," Industrial Management and Data Systems, vol. 111, no. 8, pp. 1238-1269, 2011.

[124] M.-C. Tsai, W. Lee, and H.-C. Wu, "Determinants of RFID adoption intention: evidence from Taiwanese retail chains," Information and Management, vol. 47, no. 5-6, pp. 255-261, 2010.

[125] C. S. Yap, "Issues in managing information technology," Journal of the Operational Research Society, vol. 40, no. 7, pp. 649-658, 1989.

[126] B. S. Ragu-Nathan, C. H. Apigian, T. S. Ragu-Nathan, and Q. Tu, "A path analytic study of the effect of top management support for information systems performance," Omega, vol. 32, no. 6, pp. 459-471, 2004.

[127] M. Bradford and J. Florin, "Examining the role of innovation diffusion factors on the implementation success of enterprise resource planning systems," International Journal of Accounting Information Systems, vol. 4, no. 3, pp. 205-225, 2003.

[128] S.-H. Jang, "An empirical study on the factors influencing RFID adoption and implementation," Management Review: An International Journal, vol. 5, no. 2, pp. 55-73, 2010.

[129] H. Barki and J. Hartwick, "Measuring user participation, user involvement, and user attitude," MIS Quarterly: Management Information Systems, vol. 18, no. 1, pp. 59-79, 1994.

[130] J. Y. L. Thong, C.-S. Yap, and K. S. Raman, “Top Management Support, External Expertise and Information Systems Implementation in Small Businesses," Information Systems Research, vol. 7, no. 2, pp. 248-267, 1996.

[131] C. Yap, C. Soh, and K. Raman, "Information systems success factors in small business," Omega, vol. 20, no. 5-6, pp. 597-609, 1992.

[132] A. Jeyaraj, J. W. Rottman, and M. C. Lacity, "A review of the predictors, linkages, and biases in IT innovation adoption research," Journal of Information Technology, vol. 21, no. 1, pp. $1-23,2006$.

[133] J. Y. L. Thong, "An integrated model of information systems adoption in small businesses," Journal of Management Information Systems, vol. 15, no. 4, pp. 187-214, 1999.

[134] M. Al-Mashari, A. Al-Mudimigh, and M. Zairi, "Enterprise resource planning: A taxonomy of critical factors," European Journal of Operational Research, vol. 146, no. 2, pp. 352-364, 2003.

[135] E. Karahanna, D. W. Straub, and N. L. Chervany, "Information technology adoption across time: a cross-sectional comparison of pre-adoption and post-adoption beliefs," MIS Quarterly: Management Information Systems, vol. 23, no. 2, pp. 183-213, 1999.

[136] M. Igbaria, N. Zinatelli, P. Cragg, and A. L. M. Cavaye, "Personal computing acceptance factors in small firms: A structural equation model," MIS Quarterly: Management Information Systems, vol. 21, no. 3, pp. 279-301, 1997.

[137] T. S. H. Teo and J. S. K. Ang, "An examination of major IS planning problems," International Journal of Information Management, vol. 21, no. 6, pp. 457-470, 2001.

[138] N. Schillewaert, M. J. Ahearne, R. T. Frambach, and R. K. Moenaert, "The adoption of information technology in the sales force," Industrial Marketing Management, vol. 34, no. 4, pp. 323336, 2005.

[139] E. J. Umble, R. R. Haft, and M. M. Umble, "Enterprise resource planning: Implementation procedures and critical success factors," European Journal of Operational Research, vol. 146, no. 2, pp. 241-257, 2003.

[140] I. M. Al-Jabri, "Antecedents of user satisfaction with ERP systems: mediation analyses," Kybernetes, vol. 44, no. 1, pp. 107123, 2015.

[141] J. S.-C. Hsu, S.-P. Shih, J. C. Chiang, and J. Y.-C. Liu, “The impact of transactive memory systems on IS development teams' coordination, communication, and performance," International Journal of Project Management, vol. 30, no. 3, pp. 329-340, 2012.

[142] F. Fui-Hoon Nah, J. Lee-Shang Lau, and J. Kuang, "Critical factors for successful implementation of enterprise systems," Business Process Management Journal, vol. 7, no. 3, pp. 285-296, 2001.

[143] M. Sumner, "Critical success factors in enterprise wide information management systems projects," in Proceedings of the 1999 ACM SIGCPR conference, pp. 297-303, New Orleans, La, USA, April 1999. 
[144] C. Soh, S. S. Kien, and J. Tay-Yap, "Cultural fits and misfits: Is ERP a universal solution?" Communications of the ACM, vol. 43, no. 4, pp. 47-51, 2000.

[145] T. C. Tubre and J. M. Collins, "Jackson and schuler (1985) revisited: A meta-analysis of the relationships between role ambiguity, role conflict, and job performance," Journal of Management, vol. 26, no. 1, pp. 155-169, 2000.

[146] O. Kerimoglu and N. Basoglu, "A framework for understanding adoption of organizational enterprise resource planning systems. Picmet Conference," in Proceedings of the Picmet Conference, Portland, Ore, USA, 2005.

[147] E. M. Rogers, Diffusion of Innovations, Free Press, New York, NY, USA, 5th edition, 2003.

[148] D. H. Sonnenwald, K. L. Maglaughlin, and M. C. Whitton, "Using innovation diffusion theory to guide collaboration technology evaluation: work in progress," in Proceedings of 10th IEEE International Workshop on Enabling Technologies: Infrastructure for Collaborative Enterprises, WET ICE 2001, pp. 114-119, June 2001.

[149] G. Premkumar and M. Roberts, "Adoption of new information technologies in rural small businesses," Omega, vol. 27, no. 4, pp. 467-484, 1999.

[150] M. Vouk, "Cloud computing issues, research and implementations," Journal of Computing and Information Technology, vol. 16, pp. 235-246, 2008.

[151] T. Teo, "Modelling technology acceptance in education: A study of pre-service teachers," Computers and Education, vol. 52, no. 2, pp. 302-312, 2009.

[152] G. Crump, "Cloud storage infrastructures raise many issues," InformationWeek, 2012.

[153] S. K. Lippert and C. Govindarajulu, "Technological, organizational, and environmental antecedents to web services adoption," Community. IIMA, vol. 6, pp. 146-158, 2006.

[154] R. R. Dholakia and N. Kshetri, "Factors impacting the adoption of the Internet among SMEs," Small Business Economics, vol. 23, no. 4, pp. 311-322, 2004.

[155] M. J. Pan and W. Y. Jang, "Determinants of the adoption of enterprise resource planning within the technologyorganization-environment framework: Taiwans communications industry," Journal of Computer Information Systems, vol. 48, pp. 94-102, 2008.

[156] P. Palvia, D. B. Means, and W. M. Jackson, "Determinants of computing in very small businesses," Information Management, vol. 27, pp. 161-74, 1994.

[157] F. Thiesse, T. Staake, P. Schmitt, and E. Fleisch, "The rise of the "next-generation bar code": An international RFID adoption study," Supply Chain Management, vol. 16, no. 5, pp. 328-345, 2011.

[158] S.-J. Chang, A. Van Witteloostuijn, and L. Eden, "From the Editors: common method variance in international business research," Journal of International Business Studies, vol. 41, no. 2, pp. 178-184, 2010.

[159] P. M. Podsakoff, S. B. MacKenzie, J.-Y. Lee, and N. P. Podsakoff, "Common method biases in behavioral research: a critical review of the literature and recommended remedies," Journal of Applied Psychology, vol. 88, no. 5, pp. 879-903, 2003.

[160] Z. Guo, L. Xiao, C. Van Toorn, Y. Lai, and C. Seo, "Promoting online learners' continuance intention: an integrated flow framework," Information and Management, vol. 53, no. 2, pp. 279-295, 2016.
[161] J. Kim, E. H. Park, and R. L. Baskerville, "A model of emotion and computer abuse," Information and Management, vol. 53, no. 1, pp. 91-108, 2016.

[162] Z. Liu, Q. Min, Q. Zhai, and R. Smyth, "Self-disclosure in Chinese micro-blogging: a social exchange theory perspective," Information and Management, vol. 53, no. 1, pp. 53-63, 2016.

[163] C. M. Ringle, S. Wende, and J. M. Becker, "SmartPLS 3. Bönningstedt: SmartPLS," 2015, Retrieved from http://www .smartpls.com.

[164] J. H. Kahn, "Factor analysis in counseling psychology research, training, and practice: principles, advances, and applications," The Counseling Psychologist, vol. 34, no. 5, pp. 684-718, 2006.

[165] V. E. Vinzi, W. W. Chin, J. Henseler, and H. Wang, Eds., Handbook of partial least squares, Springer Handbooks of Computational Statistics, Springer, Berlin, Germany, 2010.

[166] W. Reinartz, M. Haenlein, and J. Henseler, "An empirical comparison of the efficacy of covariance-based and variancebased SEM," International Journal of Research in Marketing, vol. 26, no. 4, pp. 332-344, 2009.

[167] W. W. Chin and P. R. Newsted, "Structural equation modeling analysis with small samples using partial least squares," in Statistical Strategies for Small Sample Research, R. Hoyle, Ed., pp. 307-341, Sage Publications, Thousand Oaks, Calif, USA, 1999.

[168] T. Cui, H. Ye, H. H. Teo, and J. Li, "Information technology and open innovation: a strategic alignment perspective," Information and Management, vol. 52, no. 3, pp. 348-358, 2015.

[169] D. Sedera, S. Lokuge, V. Grover, S. Sarker, and S. Sarker, "Innovating with enterprise systems and digital platforms: a contingent resource-based theory view," Information and Management, 2015.

[170] K. Wang, "Determinants of mobile value-added service continuance: The mediating role of service experience," Information and Management, vol. 52, no. 3, pp. 261-274, 2015.

[171] V. Esposito Vinzi, W. W. Chin, J. Henseler, and H. Wang, Handbook of Partial Least Squares, Springer, Berlin, Germany, 2010.

[172] J. Hair, W. Black, B. Babin, R. Anderson, and R. Tatham, Multivariate Data Analysis, Prentice Hall, Upper Saddle River, NJ, USA, 5th edition, 2005.

[173] R. P. Bagozzi and Y. Yi, "On the evaluation of structural equation models," Journal of the Academy of Marketing Science, vol. 16, no. 1, pp. 74-94, 1988.

[174] J. F. Hair, C. M. Ringle, and M. Sarstedt, "PLS-SEM: indeed a silver bullet," Journal of Marketing Theory and Practice, vol. 19, no. 2, pp. 139-151, 2011.

[175] C. Fornell and D. F. Larcker, "Evaluating structural equation models with unobservable variables and measurement error," Journal of Marketing Research, vol. 18, no. 1, pp. 39-50.

[176] J. Henseler, C. M. Ringle, and R. R. Sinkovics, "The use of partial least squares path modeling in international marketing," Advances in International Marketing, vol. 20, no. 1, pp. 277-319, 2009.

[177] K. A. Bollen, "A new incremental fit index for general structural equation models," Sociological Methods \& Research, vol. 17, no. 3, pp. 303-316, 1989.

[178] E. Carmines and R. Zeller, Reliability and Validity Assessment, vol. 17, SAGE Publications, Inc., Thousand Oaks, Calif, USA, 1979.

[179] W. W. Chin, “The partial least squares approach to structural equation modeling," Modern Methods for Business Research, vol. 295, no. 2, pp. 295-336, 1998. 
[180] J. F. Hair, M. Sarstedt, C. M. Ringle, and J. A. Mena, "An assessment of the use of partial least squares structural equation modeling in marketing research," Journal of the Academy of Marketing Science, vol. 40, no. 3, pp. 414-433, 2012.

[181] J. Henseler, C. M. Ringle, and M. Sarstedt, "Using partial least squares path modeling in advertising research: basic concepts and recent issues," Handbook of Research on International Advertising, pp. 252-276, 2012.

[182] R. Falk and N. Miller, A Primer for Soft Modeling, University of Akron Press, Akron, Ohio, USA, 1992.

[183] S. Geisser, "A predictive approach to the random effect model," Biometrika, vol. 61, pp. 101-107, 1974.

[184] M. Stone, "Cross-validatory choice and assessment of statistical predictions," Journal of the Royal Statistical Society, vol. 36, pp. 111-147, 1974.

[185] H.-C. Cho and S. Abe, "Is two-tailed testing for directional research hypotheses tests legitimate?" Journal of Business Research, vol. 66, no. 9, pp. 1261-1266, 2013.

[186] S. Seol, H. Lee, J. Yu, and H. Zo, "Continuance usage of corporate SNS pages: A communicative ecology perspective," Information Management, vol. 53, no. 6, pp. 740-751, 2016.

[187] J. Hair, G. Hult, C. Ringle, and M. Sarstedt, A Primer on Partial Least Squares Structural Equation Modeling (PLS-SEM), Sage, Los Angeles, Calif, USA, 1st edition, 2014.

[188] J. M. Ortega Egea and M. V. Román González, “Explaining physicians' acceptance of EHCR systems: an extension of TAM with trust and risk factors," Computers in Human Behavior, vol. 27, no. 1, pp. 319-332, 2011.

[189] H.-B. Kim, T. Kim, and S. W. Shin, "Modeling roles of subjective norms and eTrust in customers' acceptance of airline B2C eCommerce websites," Tourism Management, vol. 30, no. 2, pp. 266-277, 2009.

[190] L. Robinson Jr., G. W. Marshall, and M. B. Stamps, "An empirical investigation of technology acceptance in a field sales force setting," Industrial Marketing Management, vol. 34, no. 4, pp. 407-415, 2005.

[191] C. Hutchinson, J. Ward, and K. Castilon, "Navigating the nextgeneration application architecture," IT Professional, vol. 11, no. 2, Article ID 4804044, pp. 18-22, 2009.

[192] A. Khajeh-Hosseini, D. Greenwood, J. W. Smith, and I. Sommerville, "The Cloud Adoption Toolkit: supporting cloud adoption decisions in the enterprise," Software: Practice and Experience, vol. 42, no. 4, pp. 447-465, 2012. 

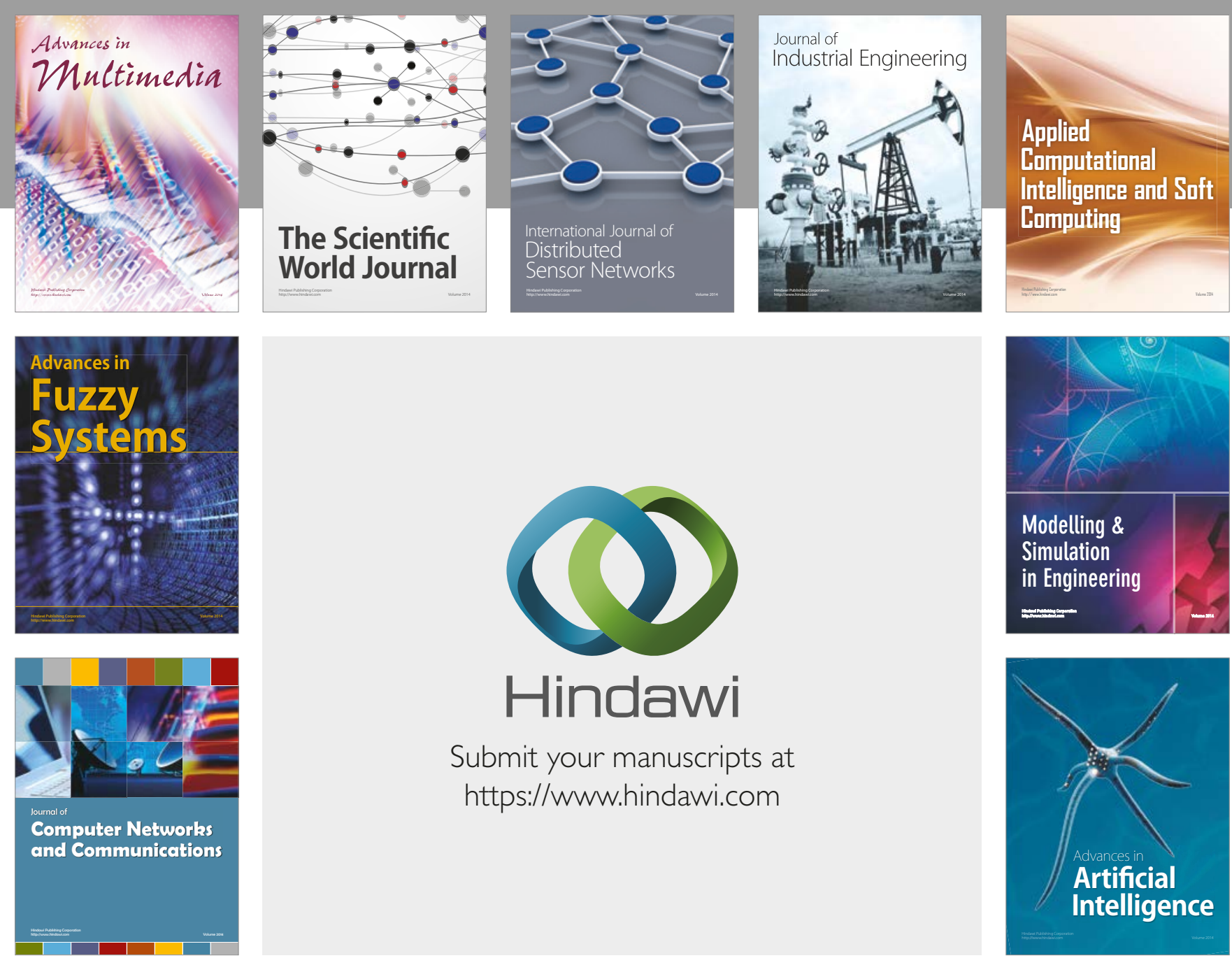

\section{Hindawi}

Submit your manuscripts at

https://www.hindawi.com
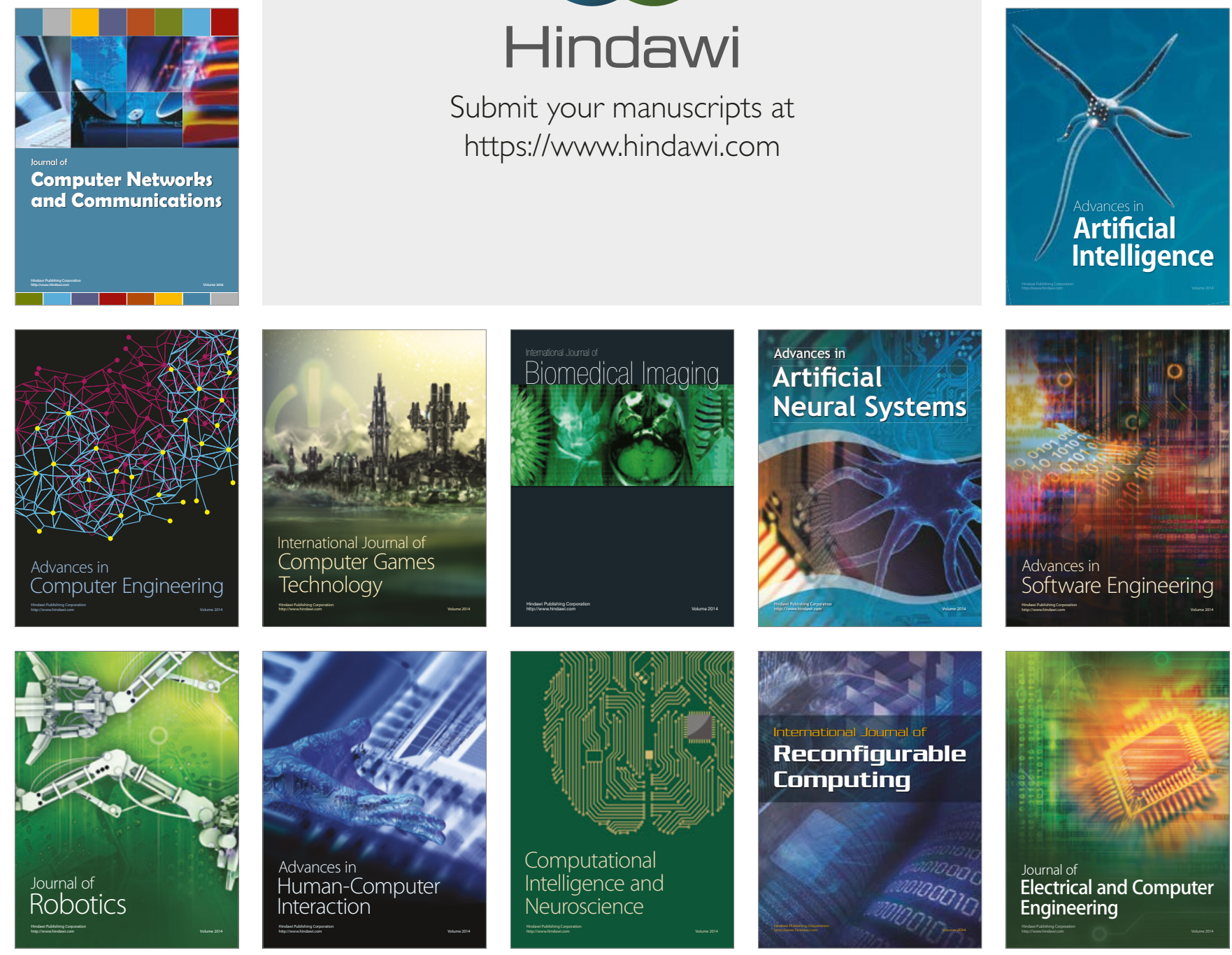